\title{
STRUCTURAL ANALYSIS OF SALT CAVITIES FORMED BY SOLUTION MINING: \\ II. TIME-DEPENDENT BEHAVIOR OF PROGRESSIVELY-MINED CAVITIES \\ OF DIFFERENT SHAPES UNDER ARBITRARY INITIAL STRESS FIELDS
}

\author{
Submitted To \\ Office of Waste Isolation \\ Oak Ridge, Tennessee \\ operated by \\ Union Carbide Corporation \\ Nuclear Division \\ for the
}

Energy Research and Development Administration

By

Arlo F. Fossum

This report was prepared by RE/SPEC InC., under Subcontract No. 89Y-22303C with Union Carbide Corporation, Nuclear Division, under Contract No. W-7405-eng-26 with the Energy Research and Development Administration. The subcontract was administered by the Office of Waste Isolation, Union Carbide Corporation, Nuclear Division.

\section{$\mathrm{RE} / \mathrm{SPEC}$ ING.}

P. O. BOX 725 - RAPID CITY, S. D. 57701 - 605/343-7868 


\section{DISCLAIMER}

This report was prepared as an account of work sponsored by an agency of the United States Government. Neither the United States Government nor any agency Thereof, nor any of their employees, makes any warranty, express or implied, or assumes any legal liability or responsibility for the accuracy, completeness, or usefulness of any information, apparatus, product, or process disclosed, or represents that its use would not infringe privately owned rights. Reference herein to any specific commercial product, process, or service by trade name, trademark, manufacturer, or otherwise does not necessarily constitute or imply its endorsement, recommendation, or favoring by the United States Government or any agency thereof. The views and opinions of authors expressed herein do not necessarily state or reflect those of the United States Government or any agency thereof. 


\section{DISCLAIMER}

Portions of this document may be illegible in electronic image products. Images are produced from the best available original document. 
TECHNICAL MEMORANDUM REPORT RST-0051

STRUCTURAL ANALYSIS OF SALT CAVITIES FORMED BY SOLUTION MINING:

II. TIME-DEPENDENT BEHAVIOR OF PROGRESSIVELY-MINED CAVITIES

OF DIFFERENT SHAPES UNDER ARBITRARY INITIAL STRESS EIELDS

submitted To

Office of Waste Isolation

Oak Ridge, Tennessee

operated by

Union Carbide Corporation

Nuclear Division

for the
This report was prepared as an accounn, of work sponsored by the United States Govemment. Neither the United States nor the United States Department of Energy, nor any of their employees, nor any of their contractors, subcontractors, or their employees, makes any warranty, express or implied, or assumes any legal or usefulness of any information, apparatus, product or process disclosed, of represents that its use product or process disclosed, of represents that its use would not
infringe privately owned rights.

Energy Research and Development Administration

$B y$

Arlo $F$, Fossum

of

RE/SPEC InC.

P. O. BOX 725

Rapid City, South Dakota

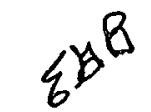

August 1, 1977

DLSTRIBUTION OF THIS DOCUMLENT IS UNLIMITEI

This report was prepared as an account of work sponsored by the United States Government. Neither the United States nor the Energy Research and Development Administration, nor any of their employees, nor any of their contractors, subcontractors, or their employees, makes any warranty, express or implied, or assumes ary legal liability or responsibility for the accuracy, completeness or usefulness of any information, apparatus, product or process aisclosed, or represents that its use would not infringe privately owned rights. Any mention of trade names in this report is for reference purposes only and should not be construed as any manner of endorsement. 
(RSI-0051)

\section{TABLE OF CONTENTS}

$\underline{\text { Page }}$

1. INTRODUCTION

1

2. MATERIAL BEHAVIOR 3

3. NUMERICAL ALGORITHM

4. FINITE ELEMENT SOLUTION OF SELECTED SOLUTION CAVITY PROBLEMS 12

4.1. Evaluation of Finite Element Solution with 12

Analytical Results

4.2. Evaluation of Finite Element Solution with

Independent Finite-Element Results

4.3. Creep Behavior of a Spherical Cavity Under Different Initial Stress Conditions

4.4. Influence of Cavity Shape on Creep Behavior 
1 Illustration of Strain and Time Hardening

2. Finite Element Mesh of a Spherical Cavity with.Elements to be Excavated Shown Shaded

3 Comparison Between Finite Element and Exact

Solution for the Vertical Stress Concentration

Factors for a spherical Cavity in a Bar

Horizontal (Radial) Stress Around a Spherical Cavity

5 Influence of Excavation Sequence on Horizontal

Stress Around a Cavity of a Cavity (Downward Displacement) of a Cavity (Inward Displacement) Four years After Fluid Excavation $(K=1)$ 


\section{IIST OF FIGURES (COn't)}

Figure

Page

19 Vertical Stress Around Cavities After Third and Fourth Excavations ( $K=1)$

20 Vertical Stress Around Cavities After Fifth Excavation and Immediately Following Fluid Evacuation $(K=1)$

21 Vertical Stress Around Cavities One Year After Fluid Evacuation $(K=1)$

Effective Stress Around the Cavities $(K=1)$

Upward Displacement of Cavities Versus Time $(K \cong 1)$ Time $(K=1)$

\section{FOREWORD}

This report is the second one in a memoranda series dealing with the structural analysis of cavities in salt formed by solution mining. The main objectives of this report are: (1) to demonstrate that the stress state and flow around a cavity are sensitive to the details of the excavation process and to the prevailing initial in situ stress state; and (2) to compare the stress and displacement results for cavities of different shapes. If the initial stress state is close to lithostatic, a spherical cavity appears to be a preferred shape. No conclusions are drawn with regard to a preferred excavation sequence as only the "bottom hole injection method" was employed. It is concluded however that the excavation sequence should be taken into account in order to establish an accurute stress state from which long term creep begins.

This report was prepared by $R E / S P E C$ Inc. under subcontract No. 89Y-22303C with Union Carbide Corporation, Nuclear Division under Contract No. W-7405-eng-26 with the Energy Research and Development Administration. The subcontract was administered by the office of Waste Isolation, Union Carbide Corporation, Nuclear Division. The technical contents of the report have been reviewed by Dr. Paul F. Gnirk and $M r$. JCe L. Ratigan of RE/SFEC Inc., and the typing was performed by MS. Julie S. Annicchiarico of RE/SPEC InC. 
$\mathrm{R}$

S RE/SPEC INC.

P. O. BOX 725 •RAPID CITY, S.D. $57709 \cdot 605 / 343.7868$

August 1, 1977

TECHNICAL MEMORANDUM REPORT RSI-005I

TO: $\quad$ Office of Waste Isolation

P. O. BOX $Y$

Oak Ridge, TN 37830

Attn.: Dr. William C. McClain

FROM: $\quad$ Dr. Arlo F. FOssum

$R E / S P E C$ InC.

P. O. Box 725

Rapid City, SD 57701

SUBJECT: Structural Analysis of Salt Cavities Formed by Solution Mining: II. Time-Dependent Behavior of Progressively-Mined Cavities of Different Shapes under Arbitrary Initial Stress Fields (Union Carbide Corporation, Nuclear Division Subcontract No. 89Y-22303; RSI/001000/FY77).

1. INTRODUCTION

In Part 1 of this report series (1) and in a number of other papers $(2,3,4,5)$ concerned with the creep behavior of solution cavities in salt bodies, the cavities were assumed to have been created instantaneously. In point of fact, the evolution of a cavity may require a year or more with the evolving shape of the cavity changing continually with time.

It is the purpose of this report to develop a procedure specifically for the time dependent analysis of progressively mined cavities of arbitrary shape. The procedure will allow the cavity to be constructed in increments to its final configuration consistent with the intermediate shapes and excavation times observed in the field. It is important that the analysis procedure be general enough to incorporate varying 
degrees of idealization of material behavior. It is important also that the procedure be such that a rather arbitrary initial stress field can be included. The reason for this is evident since although every salt dome is subjected to forces due to the weight of the overburden, not all of them have the same horizontal compression. In some areas, tectonic movements cause horizontal stresses which can be quite different than those resulting in a purely gravitating medium. Gera (6) has discussed some of the aspects of salt tectonics in salt formations proposed for the disposal of radioactive wastes and gives an extensive list of references.

As with almost any engineering material, rock salt cannot be compelled to be characteristic of any particular class of behavior. For moderately high temperatures and stresses, the behavior of rock salt becomes complicated indeed. Hence, it is essential to assess the dominant characteristics of a particular class of behavior which affect structural behavior significantly under the existing conditions. In this report, no attempt will be made at formulating a creep law, as the main point of the report is to demonstrate that the stress field around the cavity is sensitive to the details of the excavation processes and to the prevailing in situ stress field. A numerical algorithm is chosen which will allow for the simultaneous construction and creep of a cavity in an incremental fashion, utilizing a residual force and initial strain approach and beginning from a selfequilibrating initial stress field superposed onto a gravitating stress field. The self-equilibrating initial stress field is chosen to represent the in situ stresses assumed or known to exist at the start of the problem. A number of examples involving cavities of different shapes are presented which illustrate the importance of the excavation simulation on the azimuthal stress distribution around the cavity and the influence of the tectonic stresses on creep behavior. 


\section{MATERIAL BEHAVTOR}

The total strain tensor, in cartesian coordinates, at any time is. assumed to be given by

$$
\varepsilon_{i j}=\varepsilon_{i j}^{e}+\varepsilon_{i j}^{p}
$$

where $\varepsilon_{i j}^{e}, \varepsilon_{i j}^{P}$ denote elastic and inelastic strain, respectively. The inelastic strain rate is assumed to be given by (see for example Reference 7)

$$
\dot{\varepsilon}_{i j}^{P}=\varepsilon_{1} \phi_{1}\left(y_{1}\right) \partial z_{1} / \partial \sigma_{i j}
$$

$$
\begin{aligned}
& \text { where } \quad \dot{\varepsilon}_{i j}^{P} \quad \text { is inelastic strain-rate } \\
& \xi_{1} \quad \text { is a viscosity parameter } \\
& \phi_{1} \text { is a function of the yield function } Y_{1} \text {, with zero yield stress } \\
& \sigma_{i j} \quad \text { is the stress tensor } \\
& z_{1} \text {. is a scalar potential function of stress from which the ratio } \\
& \text { derivable. }
\end{aligned}
$$

Note that if the potential functions are equal to the yield functions, an associative "flow" rule results. Much work needs to be done at present with regard to adequate choices for these potential functions if the theory is to be developed in a broader sense than that for a stable material.

There are two basic procedural difficulties associated with implementing a creep law into a finite element code. One difficulty is taking into account the transient portion of the creep curve. The problem arises because time is not suppressed as in the case of steady state creep. An artifice which is sometimes used to circumvent this difficulty is the use of a product form of the creep strain rate given by $\varepsilon=n(\sigma) \theta(t)$. The second difficulty is accounting for varying stress conditions. Finnie ( 8 ) has delineated two physically realizable situations. In one, the history of prior deformation is short such that the creep strain should characterize the changes throughout the history of loading. In the other, the deformation proceeds over a long time 
but under stresses which do not change rapidly, such that time may provide a basis for comparison of structural change in the material. These two extremes give rise respectively to two techniques for handling varying stress conditions known as the strain hardening and the time hardening methods. Consider the situation depicted in Figure 1. The two curves emanating from the origin represent creep strains with time under two different stress levels $\sigma_{1}$ and $\sigma_{2}$ where $\sigma_{2}>\sigma_{i}$. The other two curves represent the subsequent creep behavior that would result if the stress level were changed from $\sigma_{1}$ to $\sigma_{2}$ according to the strain hardening and time hardening techniques. The curve emanating from the origin at stress level $\sigma_{2}$ is shifted either horizontally or vertically to the curve emanating from the origin at stress level $\sigma_{1}$ corresponding to the strain hardening or time hardening technique respectively. Thus at the time the stress level changes from $\sigma_{1}$ to $\sigma_{2}$ creep proceeds according to the shifted curve. In the time hardening case, the shift occurs at constant time and in the strain hardening case, the shift occurs at constant strain. A combination of the two techniques is also possibie. 


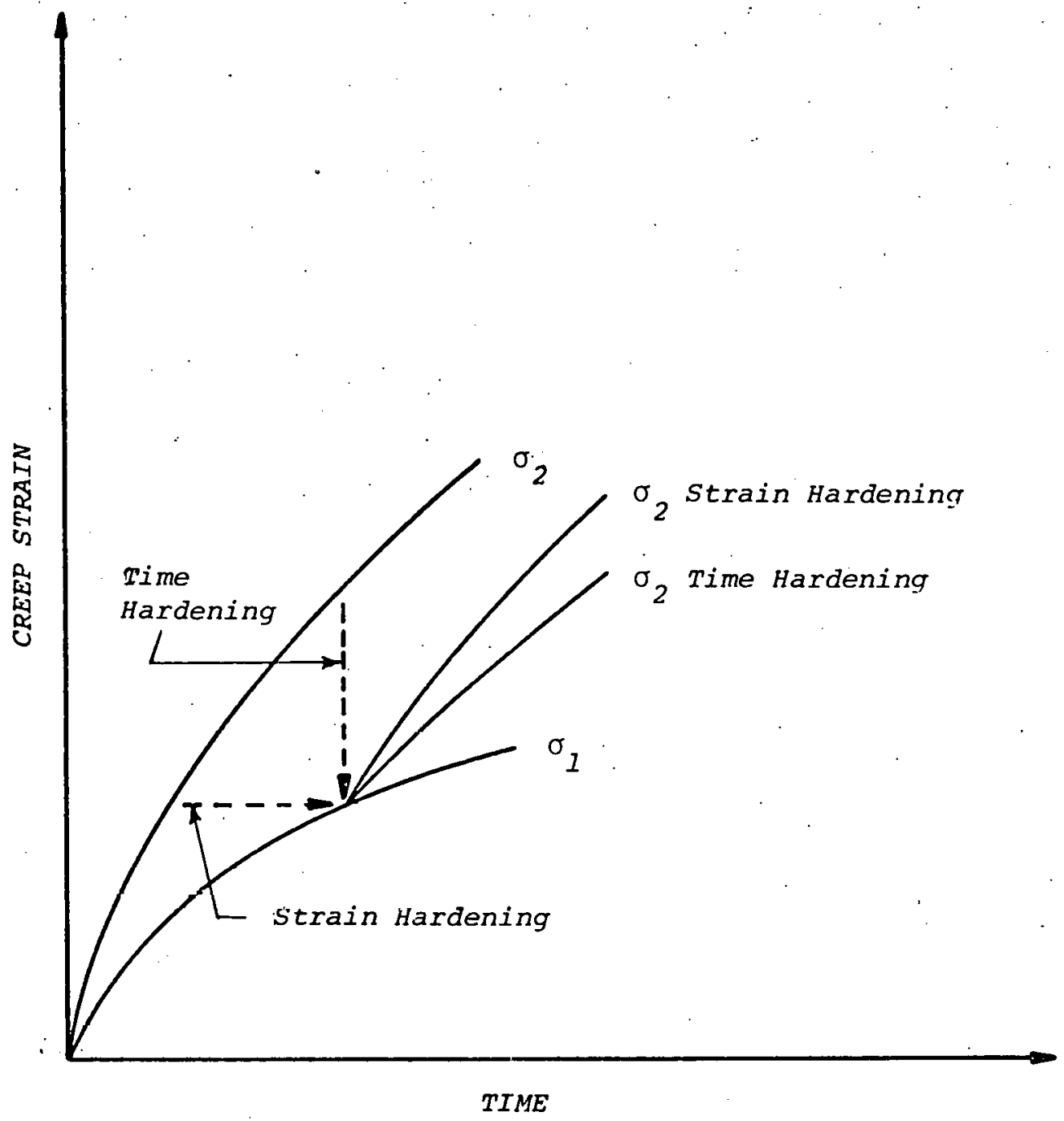

FIGURE 1. ILLUSTRATION OF STRAIN AND TIME HARDENING. 


\section{NUMERICAL ALGORITHM}

In this section an algorithm is developed which will allow for the simultaneous construction and creep of a cavity. This procedure is similar to that of zienkiewicz, et.al. (9) and the interested reader is referred to this paper and to one by cormeau (10) in which the numerical stability problem is discussed for this solution technique. From the principle of virtual work, one is led to the repeated solution of a modified elastic problem involving time varying displacements $\{\delta\}$ given by .

$$
[K]\{\delta\}-\int_{\Omega}[B]^{T}[D]\left\{\varepsilon^{i e}\right\} d \Omega-\left\{F^{*}\right\}=\{0\}
$$

in which $[K]$ is the standard stiffness matrix of the structure

$$
[K]=\int_{\Omega}[B]^{T}[D][B] d \Omega,
$$

[B] is the strain-displacement matrix, [D] is the matrix of elastic properties, $\left\{\varepsilon^{i e}\right\}$ is the inelastic strain and

$$
\left\{F^{*}(t)\right\}=\{F\}+\int_{\Omega}[B]^{T}[D]\left\{\varepsilon^{0}\right\} d \Omega-\int_{\Omega}[B]^{T}\left\{\sigma_{0}\right\} d \Omega
$$

is the force vector which includes body and boundary loads, and loads due to initial stresses $\left\{\sigma_{0}\right\}$ present at the start of the problem and to initial strains $\left\{\varepsilon^{0}\right\}$. The constitutive relation for the material is assumed to have the following form

$$
\{\sigma\}=[D][B]\{\delta\}-[D]\left\{\varepsilon^{i e}\right\}+\left\{\sigma_{0}\right\}-[D]\left\{\varepsilon^{0}\right\}
$$

In the final section it will be demonstrated that creep behavior in the vicinity of the cavity is affected significantly by different initial horizontal stresses; 
hence a discussion of the initial stresses $\left\{\sigma_{0}\right\}$ is in order. It is assumed at the start of the problem that a self-equilibrating initial stress field is superposed onto a gravitating stress field. The selfequilibrating initial stress field, i.e. the horizontal stresses, are assembled into the initial stress vector. $\left\{\sigma_{0}\right\}$. Note that since the initial stress vector $\left\{\sigma_{0}\right\}$ is now self-equilibrating, the forces

$$
\{F\}_{0}=\int_{\Omega}[B]^{T}\left\{\sigma_{0}\right\} d \Omega
$$

are 1dentically zero after assembly. After an excavation, a force unbalance will result from equation (7). If the gravitating stress field plus horizontal stresses are desired to exist at zero displacement at the start of the problem, equation (5) must be identically equal to zero provided no inelastic strains exist at time $t=0$. Thus from equation (5)

$$
\{F\}=-\int_{\Omega}[B]^{T}[D]\left\{\varepsilon^{0}\right\} d \Omega .
$$

i.e., the forces due to initial strains exactly balance the body and surface forces.

A simplification in this procedure is possible if the last two terms in equátion (i) are combined in the following manner. The vertical stresses in this study are assumed to be given by

$$
\sigma_{z z}=\rho g z
$$

where $\rho$ is the mass density, $g$ is the gravitational constant, and $z$ is measured from the surface so that compression is negative. The horizontal stresses $\sigma_{r r}$ und $\sigma_{\theta \theta}$ are assumed to be given by a combination of 
gravitating and horizontal stresses in the form

$$
\sigma_{\mathbf{r}}^{0}=\sigma_{\theta \theta}^{0}=K_{\sigma z}^{0}
$$

where $K$ is arbitrary. Note that if $K$ is given by $\nu /(1-\nu)$, where $\nu$ is Poisson's ratio, a gravitating stress field results in which there are no horizontal displacements anywhere. If $K=1$, a lithostatic stress field results. The possibility also exists that $K$ could be greater than one, in which case the horizontal stresses would be greater than the vertical stresses. This last case is probable for a salt dome which is being "squeezed" upward (diapiric process). At the start of the problem an initial stress $\left\{\sigma^{0}\right\}$ defined by

$$
\left\{\sigma^{0}\right\}=\left\{\sigma_{0}\right\}-[D]\left\{\varepsilon^{0}\right\}
$$

is constructed according to equations (9) and (10). Thus an initial elastic rur is not necessary since, initially, equation (6) is given by equation $(A 1)$. In the incremental solution procedure, the total current stresses $\left\{\sigma_{i}\right\}$ will be given by

$$
\left\{\sigma_{i}\right\}=\left\{\sigma^{0}\right\}+\sum_{i}\left\{\Delta \sigma_{i}\right\}
$$

where $\left\{\Delta \sigma_{i}\right\}$ is calculated for each time step or excavation increment. The creep strains and displacements are assembled similarly with time. The solution technique consists of the following sequence:

(i) The inelastic (viscoplastic or viscous) strain change is estimated from the total current stress level $\left\{\sigma_{i}\right\}$ over a time interval $\Delta t$ by

$$
\left\{\Delta \varepsilon^{i e}\right\}=\int_{t}^{t+\Delta t}\left\{\dot{\varepsilon}^{i e}\right\} d t
$$


(ii) The total current inelastic strains are updated according to

$$
\left\{\varepsilon_{t}^{i e}+\Delta t\right\}=\left\{\varepsilon_{t}^{i e}\right\}+\left\{\Delta \varepsilon^{i e^{2}}\right\}
$$

(iii) The total current displacements are updated according to

$$
\left\{\delta_{t}+\Delta t\right\}=\left\{\delta_{t}\right\}+\{\Delta \delta\}
$$

where $\{\Delta \delta\}$ is calculated from

$$
[K]\{\Delta \delta\}=\int_{\Omega}[B]^{T}[D]\left\{\Delta \varepsilon^{i E}\right\} d \Omega
$$

(iv) The total current stresses are updated according to equation (14) where $\left\{\Delta \sigma_{i}\right\}$ is calculated from

$$
\left\{\Delta \sigma_{i}\right\}=[D][B]\{\Delta \delta\}-[D]\left\{\Delta \varepsilon^{i e}\right\}
$$

The process is then repeated beginning from step (i). The excavation procedure is assumed to occur (as an approximation to a field situation) as a sequence of instantaneous excavations. When the appropriate time is reached for one of these excavations, the stiffness matrix $[K]$ is updated by the removal of elements and a consistent load vector $\{\Delta Q\}$ is formed corresponding to the washing fluid pressure and the reverse of the normal and shear stresses existing prior to excavation on the tangent plane to the new cavity surface. The increment in displacements $\{\Delta \delta\}$ is calculated from

$$
\left[K_{\text {new }}\right]\{\Delta \delta\}=\{\Delta Q\}
$$

and the increment in stresses is calculated from

$$
(\Delta \sigma)=[D][B][\Delta \delta\}
$$


(RSI-0051)

and then added to the total current displacements $\{\delta\}$ and stresses $\{\sigma\}$; respectively. Note that no inelastic strains are calculated. That is, since each individual excavation is instantaneous, the maximum stress level is reached accompanied only by elastic strains. Flow then proceeds with time.

Physically, the process of excavation involves removing material for an already stressed structure. By the removal of material, a new structure has been created which corresponds to a new stiffness matrix. The newly created boundary surface is characterized by the vanishing of normal and shear stresses on that boundary, except in the case of the solution mined cavity in which a normal pressure is imposed on the surface corresponding to the static head of washing fluid. Note that the stress state existing just before mining would remain unchanged only if the normal and shear stresses existing at the position in the pre-mining configuration corresponding to the newly created surface in the postmining configuration were applied to the new configuration. In this context, normal and shear stresses refer to stresses directed normal and tangent respectively to the new surface.

The author has adopted the following procedure for reformulating the stiffness matrices. The elements which are excavated first are numbered last. The elements which are excavated second are numbered second to last and so on. The assembly of the stiffness matrix proceeds element by element beginning with element 1 . When the assembly reaches the element to be excavated last, this matrix is written on a direct access unit with zeros occupying the unfilled positions, The assembly then continues until the last element of the group of elements to be excavated second to last is reached, and then this matrix is written on another direct access unit again with zeros occupying the unfilled positions. This procedure continues until the last element is reached. When the time to excavate is reached, the appropriate stiffness matrix is read into core. At this time, the positions of the stiffness matrix corresponding to the diagonals are checked for zeros. When a zero occurs at $K_{l l}$ it is replaced by unity. The equilibrium equation is additionally modified by placing a zero in the lth position of the load vector. This procedure prevents the stiffness matrix from becoming singular and simply results in zero displacements for the excavated nodes. The stresses at the excavated nodes are then set to zero. 
At the time of excavation, the state of stress on the new cavity boundary is examined. If the boundary is skewed with respect to the global coordinates or if the boundary is curved, a tensor transformation is performed in order to obtain the normal and shear stresses existing on the new face: The use of isoparametric elements greatly facilitates this procedure. Not only can nodal stresses be obtained, but the spatial derivatives of the interpolation polynomial used previously to obtain the strain displacement matrices may be used to obtain the appropriate slope angles of the new cavity boundary. 
4. FINITE ELEMENT SOLUTION OF SELECTED SOLUTION CAVITY PROBLEMS

4.1. Evaluation of Finite Element Solution with Analytical Results

The problems considered in this section were selected to illustrate the influence of the excavation simulation on the azimuthal stress distribution around a cavity and the importance of the horizontal stresses and cavity shape on creep behavior. In order that an assessment of mesh adequacy can be made as well as the adequacy of the solution routine, a sphere will be used initially so that the results of test cases can be compared with known solutions. The proposed test mesh is illustrated in Figure 2. Shaded elements are shown in the interior of the spherical boundary which will be excavated in the sequence indicated by the boldfaced boundaries. Once these elements have been excavated, the mesh will represent a spherical cavity in a cylindrical bar. Before excavation the mesh contains 233 biquadratic isoparametric ring elements with 760 nodes and 1520 degrees of freedom. After the final excavation, the mesh contains 128 elements with 433 nodes and 866 degrees of freedom. In the first test problem all of the nodes in the mesh were given a vertical tensile stress, all other stresses being zero. Thus initially $\{\sigma\}=\left\{\sigma^{0}\right\}$. The nodes along $r=0$ were rollered to prevent horizontal displacement because of symmetry. Next a single excavation to the final configuration was made according to the procedure given in section 3. That is, incremental displacements and stresses were obtained from equations (18) and (19) and added to the total displacements $\{\delta\}$ and stresses $\{\sigma\}$. The solution to this problem should be precisely the same as the problem in which tensile stresses are applied to the ends of a bar containing a spherical cavity. Timoshenko and Goodier (11) give the exact solution for this problem which, in the form of a vertical stress concentration factor along $z=0$, is given by

$$
s c=1+\frac{4-5 v}{2(7-5 v)}\left(\frac{r_{0}}{r}\right)^{3}+\frac{9}{2(7-5 v)}\left(\frac{r_{0}}{r}\right)^{5}
$$

where $r$ is the horizontal axis, $r_{0}$ corresponds to the radius of the sphere, and $\nu$ is Poisson's ratio. Note that, due to the three dimensional nature of this problem, Poisson's ratio has an important effect on the stress distribution. The vertical stress concentration factor along $z=0$ obtained from the finite element solution is plotted in Figure 3 with 


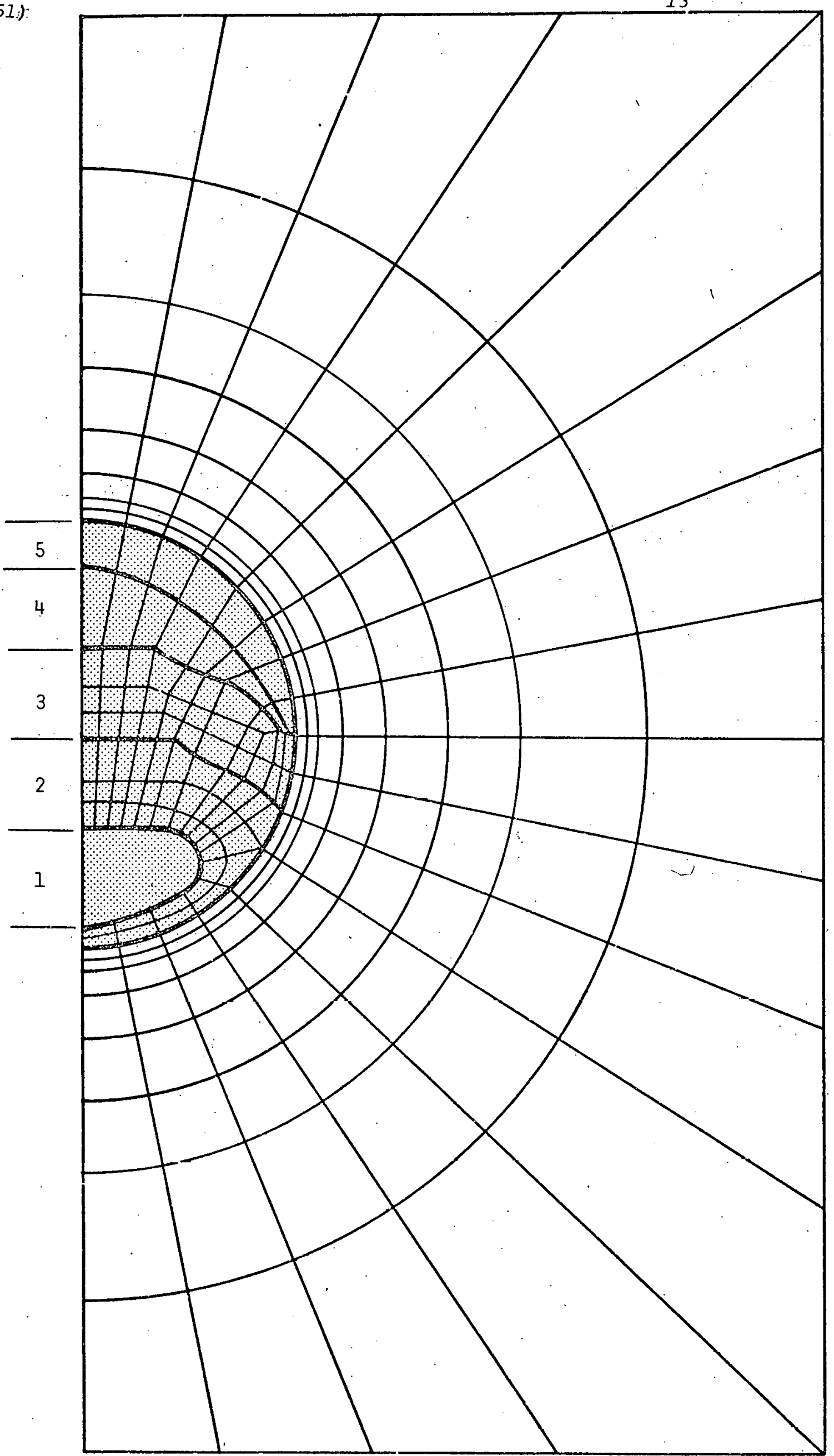

PIGURE 2. FINIIE ELEMENT MESH OF A SPHERICAL CAVITY WITH ELEMENTS TO BE EXCAVATED SHOWN SHADED. 
the values obtained from equation (20). The Poisson's ratio used in this problem was 0.45 . As illustrated in the figure, agreement is almost identical. Thus the mesh is adequate with regard to refinement near the free surface, and since the stress concentration factor is sufficiently close to unity at the outer boundary of the mesh, the model can be thought of as a sphere in an infinite solid.

\subsection{Evaluation of Finite Element Solution with Independent Finite-Element Results}

The next problem is chosen to illustrate the adequacy of the creep routine and the methoa of dealing with initial stresses. The problem, one of several considered by Nair, et.al. (2) involves the instantaneous construction and creep of a spherical cavity in a lithostatic stress field. Lithostatic refers to a state of stress in which all principal stresses are equal at depth $z$ and which has the value $\rho g z$, where $\rho$ is the mass density and $g$ is the gravitational constant. Again the mesh of Figure 3 was used, wherein the interior elements were excavated in one step as in the previous example. The spherical cavity had a diameter of 96 meters located at a depth of 823 meters. The variation of vertical stress with depth was taken as $0.0226 \mathrm{MPa} /$ meter. Young's modulus and Poisson's ratio were respectively $2.76 \times 10^{4} \mathrm{MPa}$ and 0.45 . The creep law, taken from Project Dribble (2), is given in terms of effective creep strain and effective stress by

$$
\varepsilon_{e}=1.87 \times 10^{-13} t^{0.36} \sigma_{e}^{2.98}
$$

where the effective creep strain and effective stress are given by

$$
\begin{aligned}
& \varepsilon_{e}=(2 / 3) \sigma_{e} \varepsilon_{i j}^{\nabla} / s_{i j}, \\
& \sigma_{e}=\left(3 J_{2}\right)^{i / 2}
\end{aligned}
$$

where $\varepsilon_{i j}^{V}$ is the multi-axial creep strain, $J_{2}$ is the second invariant of the stress deviator, and $s_{i j}$ is the stress deviator. The above creep law (21) can be obtained from, equation (2) with the following assumptions. The potential function $z_{1}$ is assumed to be given by the yield function $Y_{I}$. The function $\phi_{1}\left(\underline{y}_{1}\right)$ is assumed to be given by a power law $Y_{1}^{\frac{1}{n}}$ with $n=2.98$. A Von Mises yield function is assumed 
with zero yield stress. so. that

$$
y_{1}^{n}=\left(3 J_{2}\right)^{n / 2}
$$

The flow parameter $\xi_{1}$ is assumed to be given by

$$
E_{1}=\operatorname{Aint}^{m}-1
$$

with $m=0.36$ and $A=1.87 \times 10^{-13}$. Then equation (2) becomes

$$
\dot{\varepsilon}_{i j}^{\nabla}=A m t^{m}-1\left(3 J_{2}\right)(u-1) / 2(3 / 2) s_{i j}
$$

The additional assumption is made that the stresses do not change appreciably over the time limits of integration and equation (26) is integrated with respect to time, which, after rearrangement, becomes

$$
(2 / 3)\left(3 J_{2}\right)^{1 / 2} \varepsilon_{i j}^{v / s_{i j}}=A t^{m}\left(3 J_{2}\right)^{n / 2}
$$

By equations (22) and (23), equation (27) becomes identically equal to (21). The assumptions implied by equation (21) thus become readily apparent. In summary, these assumptions include imcompressibility during creep, isotropy, and associativity in the sense that the strain rate vector is directed normal to the surface resulting when the current stress state is substituted into the yield function $Y_{I}$.

In Figure 4 , the horizontal stress around the periphery of the cavity is shown immediately after the instantaneous excavation at $t=0$ and after 24 hours of creep. As illustrated in the figure, Nair's results differ only slightly with the author's results. This difference is probably due to the rather coarse mesh used by Nair. In addition to this, Nair used constant strain elements and hence the horizontal stress is not zero at $90^{\circ}$ since the stresses are calculated at the centers of the elements. The author has also included the results for the case in which the washing fluid pressure is imposed on the face of the cavity. The brine was assumed to have a specific gravity of 1.1. The variation of the horizontal stresses around the cavity is considerably smoother in the presence of the fluid pressure.' 


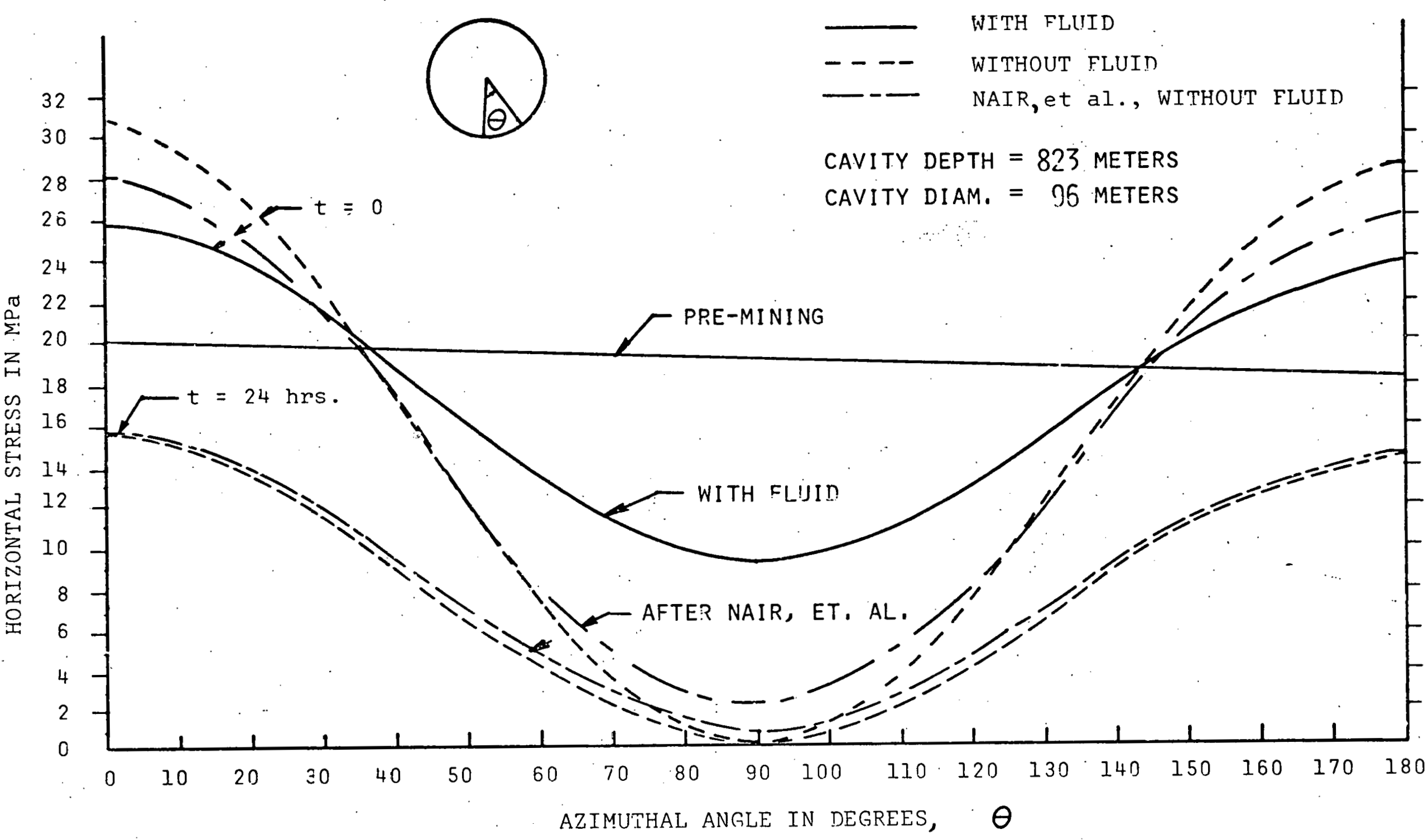


The next problem is chosen to illustrate the importance of the excavation sequence on the azimuthal stress distribution around the cavity. The excavation sequence is illustrated in the mesh of Figure 2 with the numbers representing the order in which the segments of elements are removed. This type of excavation might result from the bottom hole injection method of solution mining. The excavations occurred at times $t=.25, .5, .7$, and .9 years. The creep law used was similar to the one used by Nair,et.al.(2), and the initial stress state was lithostatic. With the final configuration as the reference configuration, the horizontal and vertical azimuthal stress aistributions are shown in Figures 5 and 6 , respectively. That is, the horizontal or vertical stress at the reference configuration after each excavation is plotted versus the azimuthal angle measured from the bottom of the cavity. Note that the washing fluid pressure has been included in this analysis. The straight lines in Figures 4, 5, and 6 represent the pre-mining state of stress which is higher at the bottom than at the top of the cavity because of gravity. The distribution of horizontal stress for this case is quite different than the distribution of horizontal stress in the previous example. Not only is the distribution less symmetric, but whereas in the previous example. the maximum horizontal stress occurred at the bottom of the cavity, now it coccurs at the top. This is due to the fact that during excavation, the stresses near the botton of the cavity have already had a chance to relax. The vertical stress distribution illustrated in Figure 6 shows similar behavior with the addition that near the equator some extremely severe stress gradients are observed. This is probably due to the rather sharp corners that exist after the third excavation.

\subsection{Creep Behavior of a Spherical Cavity Under Different Initial Stress Conditions}

The final problem with the sphere involves observing the creep behavior under different initial stress conditions. The procedure is identical to that used in the previous example with the exception that following the final excavation the fluid is evacuated. The values chosen for the lateral earth pressure coefficient $K$ as described in Section 3, were $2 / 3,1$, and 4/3. The downward, inward, and upward displacements at the top, side, and bottom of the cavity, respectively, are shown plotted versus time in Figures 7, 3, and 9. These plots illustrate just how important an initial assessment is of the premining 


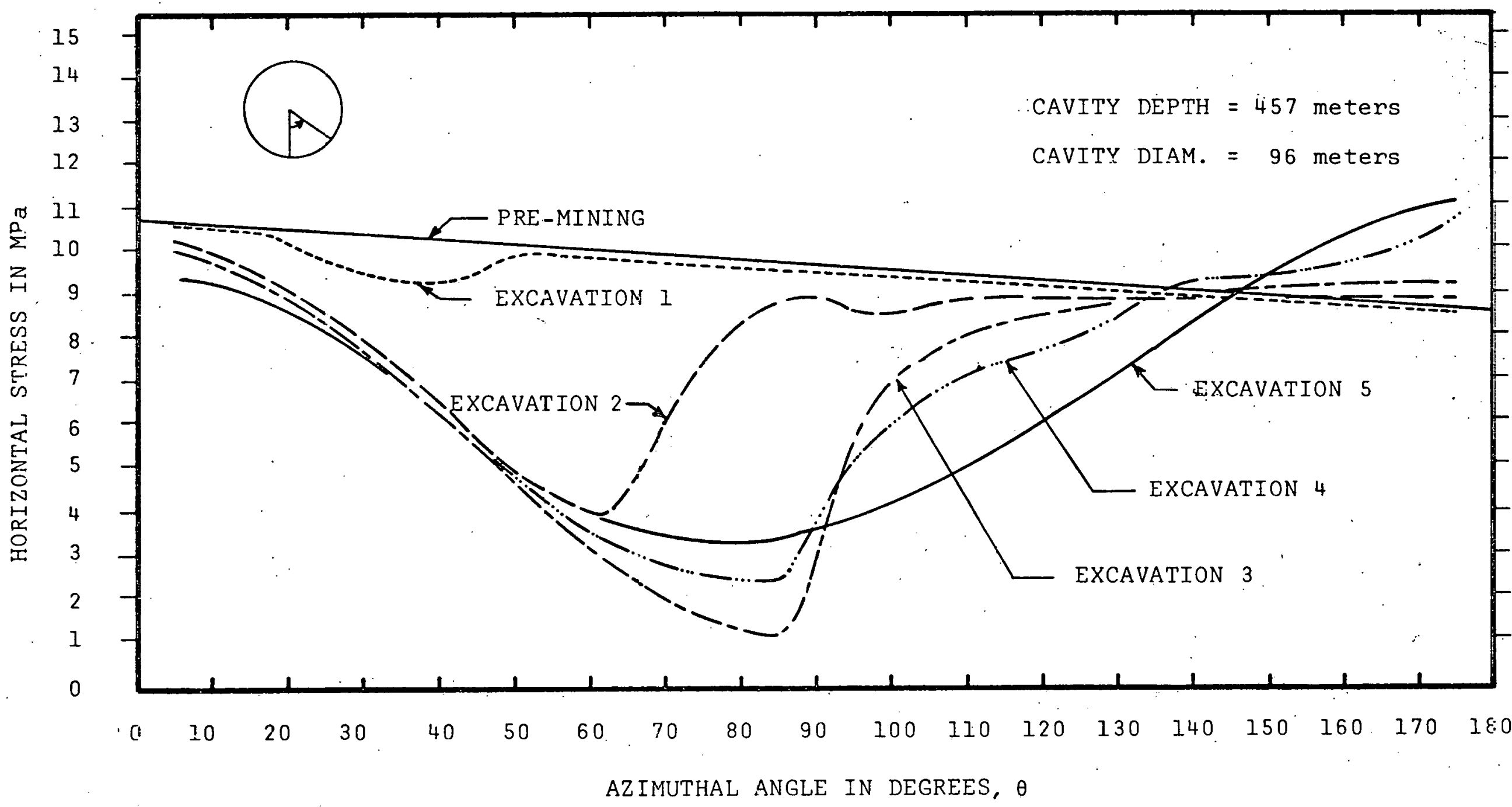

$\ddot{6}$

FIGUPE 5. INFLUENCE OF EXCAVATION SEOUENCE ON HORIZONTAL STRESS AROUND A SPHERTCAL CAVITY IN SALT. 


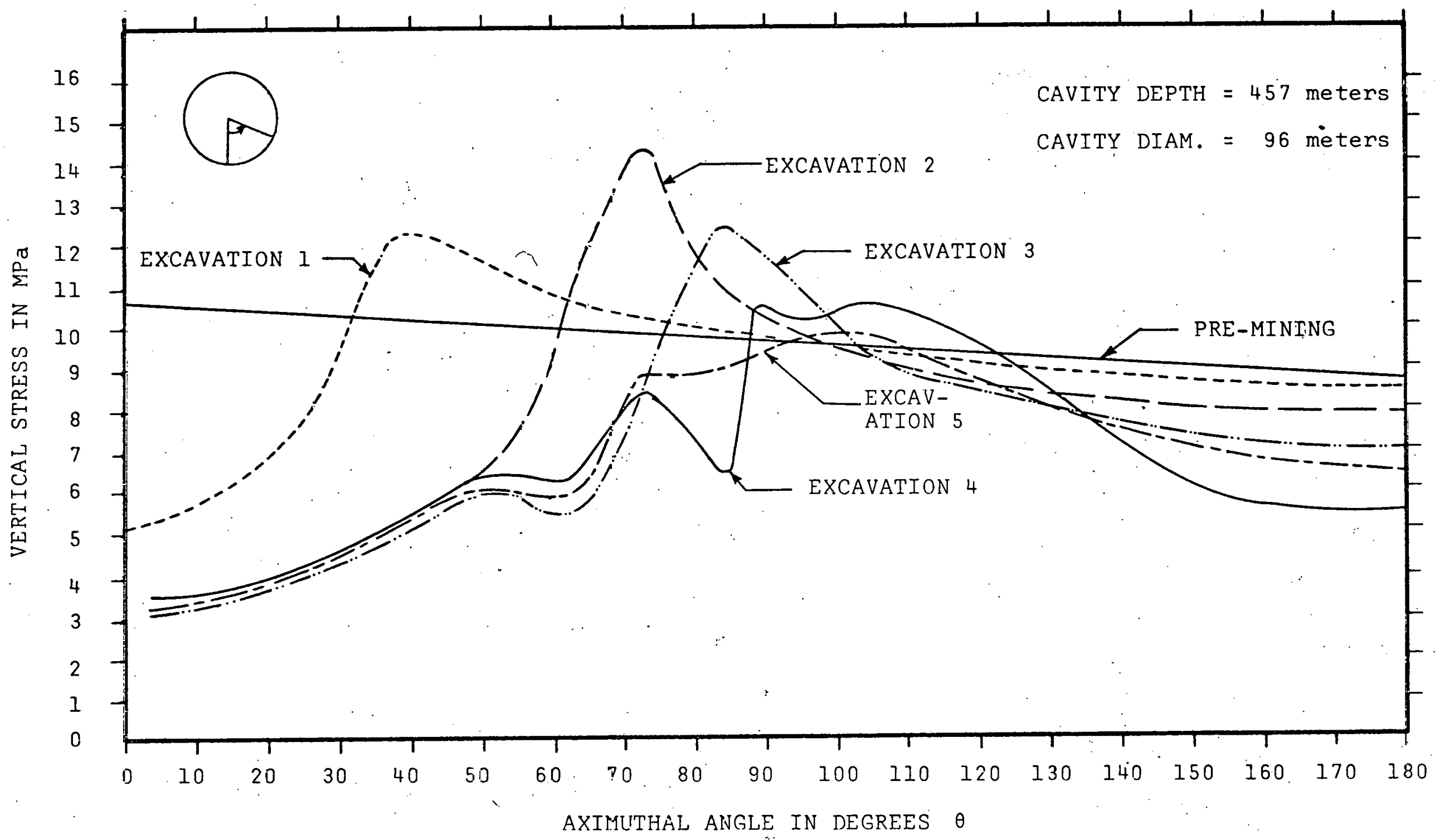

FIGURE 6. INFLUEENCE OF EXCAVATION SEOUENCE ON VERTICAI, STRESS AROUND A SPHERICAL CAVITY IN SALT. 


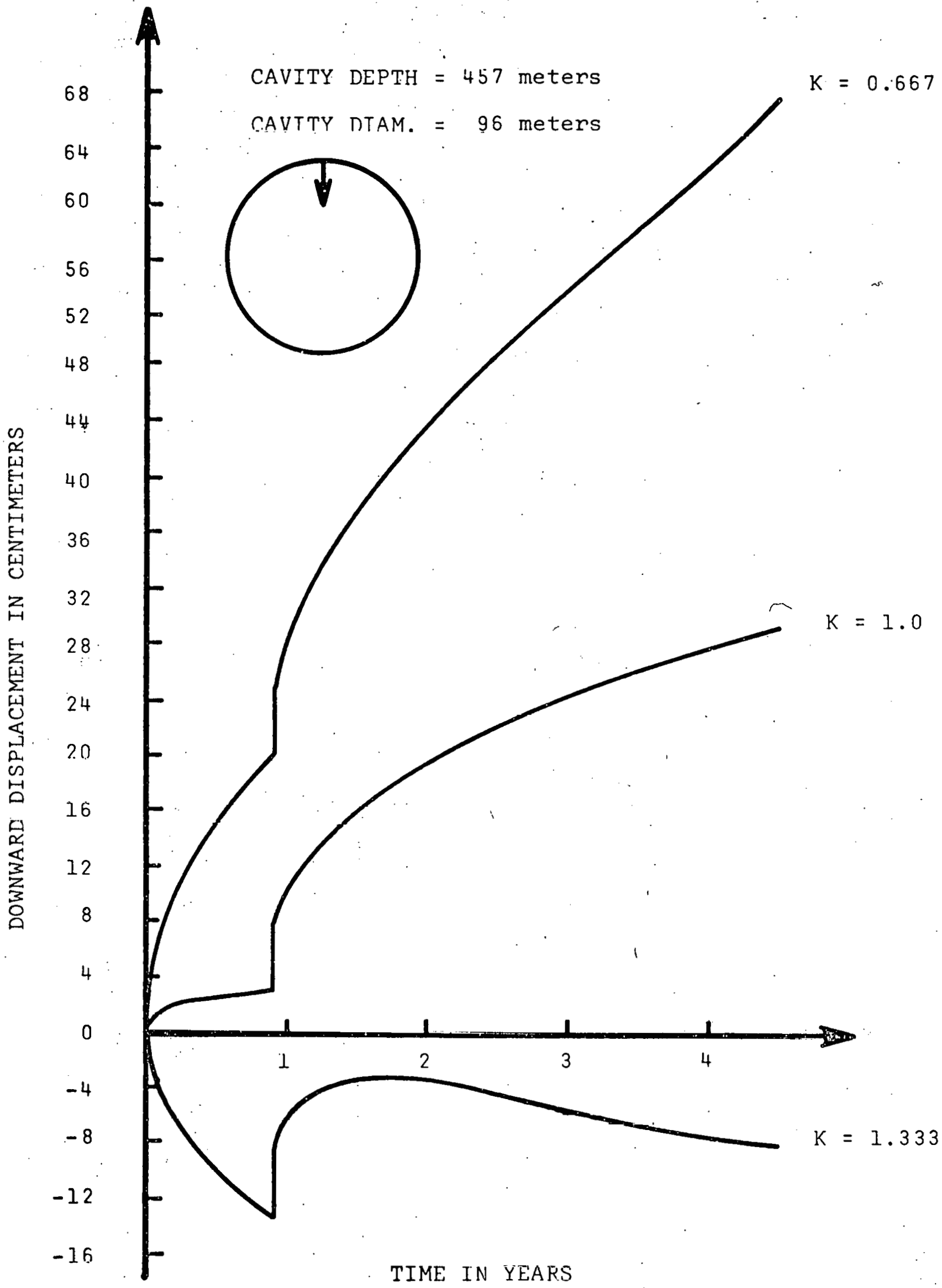

FIGURE 7. TNFLUENCE OF HORIZONTAL STRESSES ON THE CREEP BEHAVIOR OF A SPHERICAL CAVITY (LOWNWARD '.. DISPI,ACEMENT) IN SALT. 


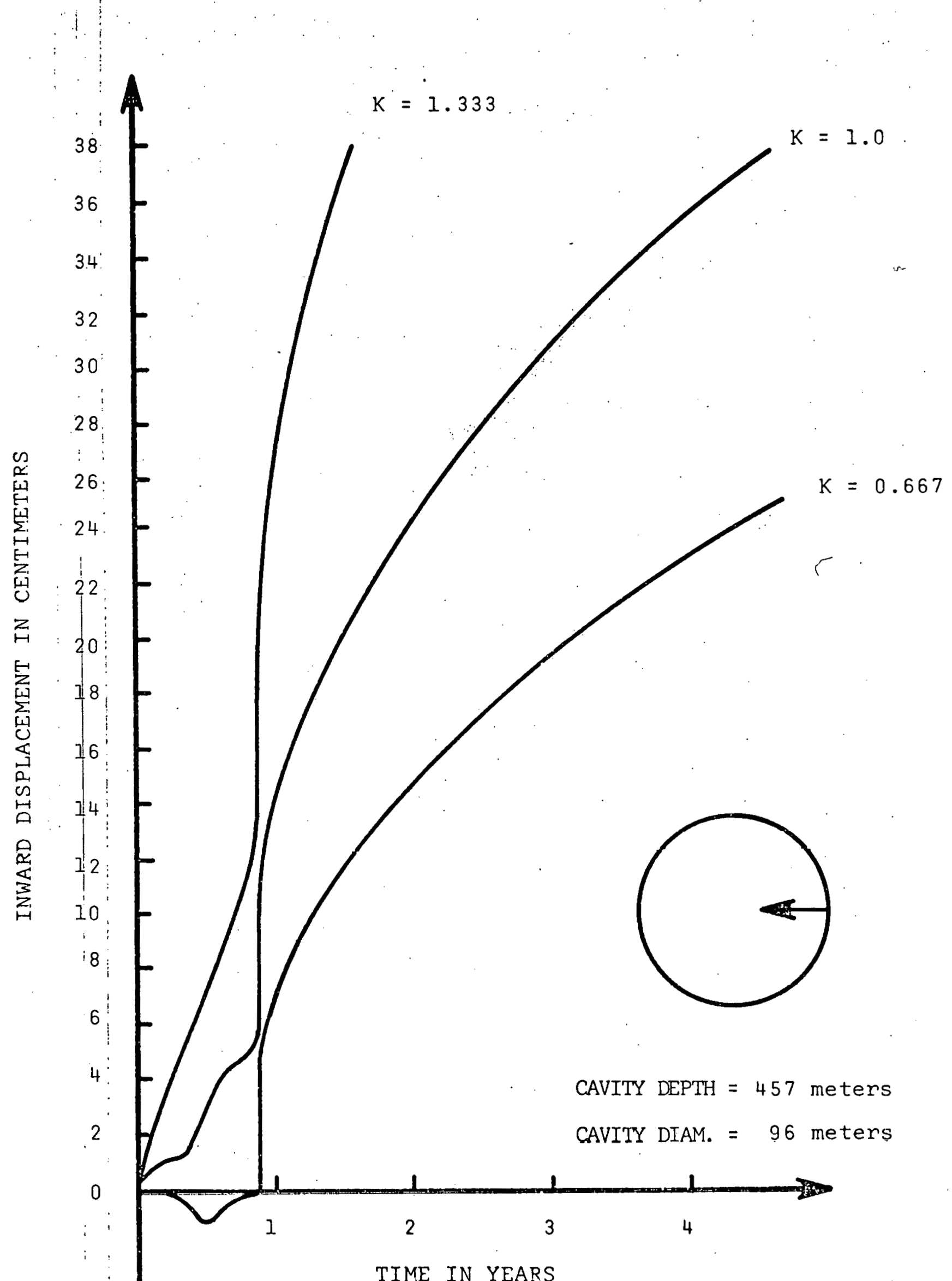

TIME IN YEARS

FIGURE 8. INFLUENCE OF HORIZONTAL STRESSES ON THE CREEP BEHAVIOR OF A SPHERTCAL CAVITY (INWARD DISPLACEMENT) IN SALT. 


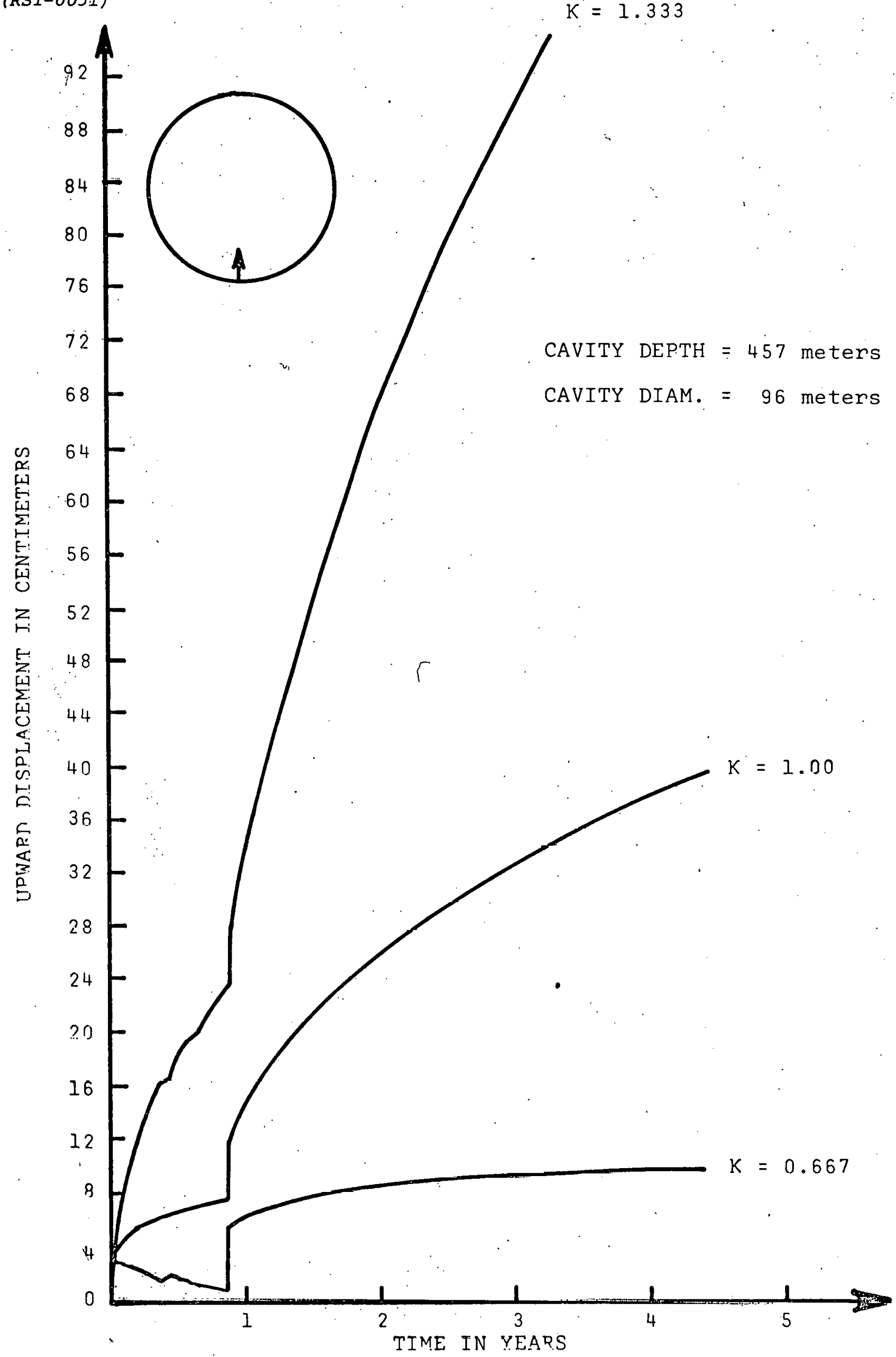

FIGURE 9. INFLUENCE OF HORIZONTAL STRESSES ON THE CREEP BEHAVIOR OF A SPHERICAL CAVITY (UPWARD DISPLACEMENT) IN SALT. 
state of stress. The creep behavior is extremely sensitive to relatively small changes in the lateral earth pressure coefficient $K$. For example, when the premining horizontal stresses are $4 / 3$ of the vertical stress, the upward displacement at the bottom of the cavity after three years following final excavation is an order of magnitude greater than the corresponding displacement for the case in which the premining horizontal stresses are $2 / 3$ of the vertical stress. It is interesting to note that for the case $K=1.333$, the entire cavity rises. In all three cases, the side of the cavity moved in and the bottom of the cavity moved up with time. The top of the cavity however rose when the horizontal stresses were greater than the vertical stress. It is clearly seen from the figures that the worst situation occurs when horizontal stresses are greater than vertical stress.

\subsection{Influence of Cavity Shape on Creep Behavior}

The next problems were chosen to illustrate the influence of cavity shape on azimuthal siress distribution and on the subsequent stress relaxation and creep behavior. In addition to the sphere of Figure 2, the prolate spheroid and oblate, spheroid illustrated in Figures 10 and 11, respectively were analyzed. A lithostatic initial stress field was chosen and the depth to the center of the cavities was 457 meters.: As before, the final configuration is used as the reference configuration. Figures 12 through 17 show the evolution of the horizontal stresses during the excavation sequence and for three years following final excavation for the differently shaped cavities. As might be expected, the sphere has the smoothest variation of horizontal stress. The prolate spheroid has essentially zero horizontal stress over its depth, whereas the oblate spheroid has a fairly constant value of horizontal stress over its top and bottom surfaces but has very sharp stress gradients near its equator. The influence of cavity shape decrease rather dramatically with time (creep). For example, compare the distributions of horizontal stress for the different shapes in Figure 15 with those in Figure 17 . In Figure 15, the fluid has fust been evacuated whereas Figure 17 represents the horizontal stress distribution three and one-half years later.

Figures 18 through 21 show similar plots of the vertical stress distribution around the cavities. Again the sphere has the smoothest variation, followed by the prolate spheroid. Figure 21 shows that with time, the influence of cavity shape is more significant with respect to the vertical stress distribution than it is for the horizontal stress 
distribution. The oblate spheroid.exhibits rather severe vertical. stress gradients even after four years of creep. The effective stress defined by equation (23), which is essentially the "driving" force in the currently used creep law, is least affected by cavity shape as iliustrated in Figure 22. With the exception of the oblate spheroid, the other values of effective stresses are practically identical.

The corresponding creep behavior for the cavities is illustrated in Figures 23 through 25. For this initial stress state, the prolate spheroid is the preferred shape with respect to vertical displacement followed by the sphere. The oblate spheroid is the most preferred shape with respect to horizontal displacement followed by the sphere. In all cases, the upward displacement at the bottom of the cavities is greater than the downward displacement at the top of the cavities: It would be difficult at this time to assess structural stability from an analytical point of view. One.would be concerned with stability in the small and stability in the large. The first involves material stability and the second involves structural stability in the "classical" sense. The notion of stability arises in different ways depending on whether or. not emphasis is given to geometric or physical properties of the structure.

The familiar initial stability problem (structural stability)

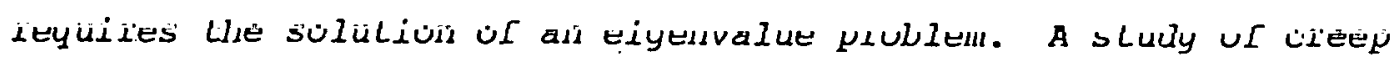
stability however is more complicated and an analytical analysis would require a major effort. At present, it seems that empirical results based on observation would be more expedient.

In summary, it seems desirable at this point to continue the study giving consideration to visco/plastic flow especially during the excavation phase of the cavity. In this regard, it is important that the method of mining be known a priori, i.e. top hole injection, 
bottom hole injection, etc. Such a procedure would account for the "adjustment" of stress which occurs at the cavity wall as salt is leached away.

Based on this study, it appears that an oblate spheroid is not a preferred shape. For conditions which are close to lithostatic, a sphere appears to be most desirable with respect to closure. 


\section{CAVITY DIMENSIONS \\ minor semi-axis $=18.1 \mathrm{~m}$ major semi-axis $=36.3 \mathrm{~m}$ \\ CAVITY DEPTH \\ 457 meters

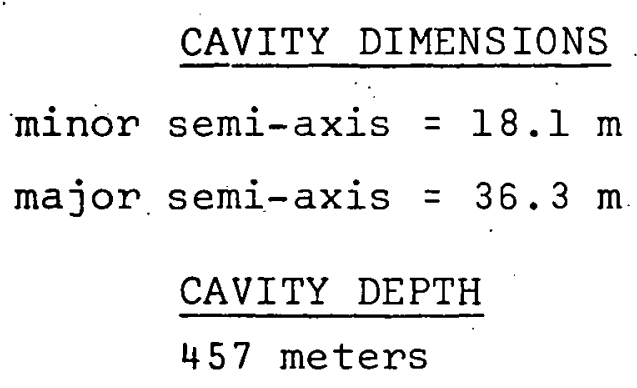

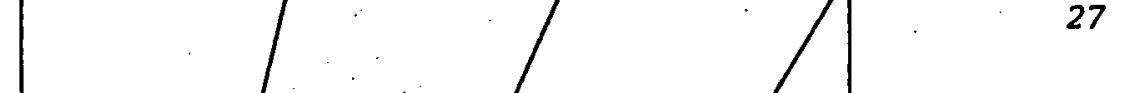
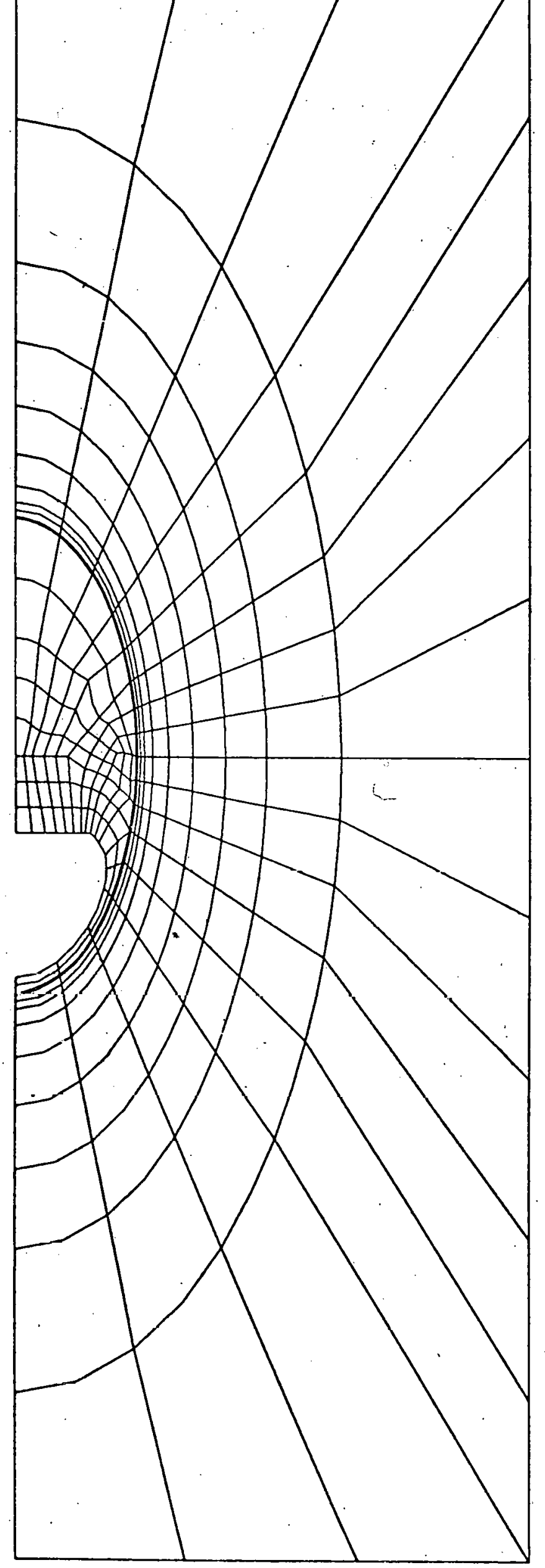

FIGURE 10.' FINITE ELEMENT MESH OF A PROLATE SPHEROIDAL CAVITY. 


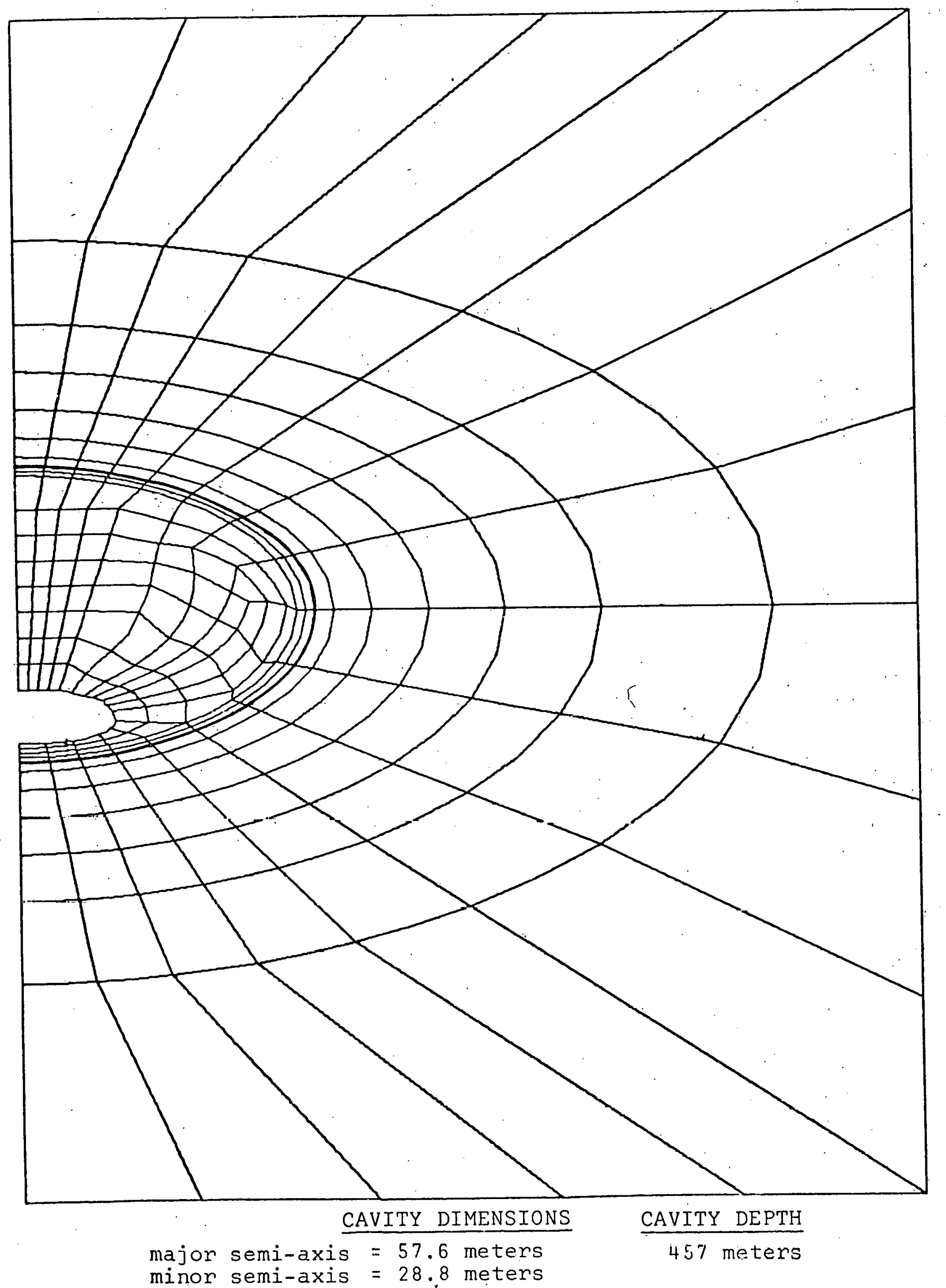

FIGURE 11. FINITE ELEMENT MESH OF AN OBLATE SPHEROIDAL CAVITY. 


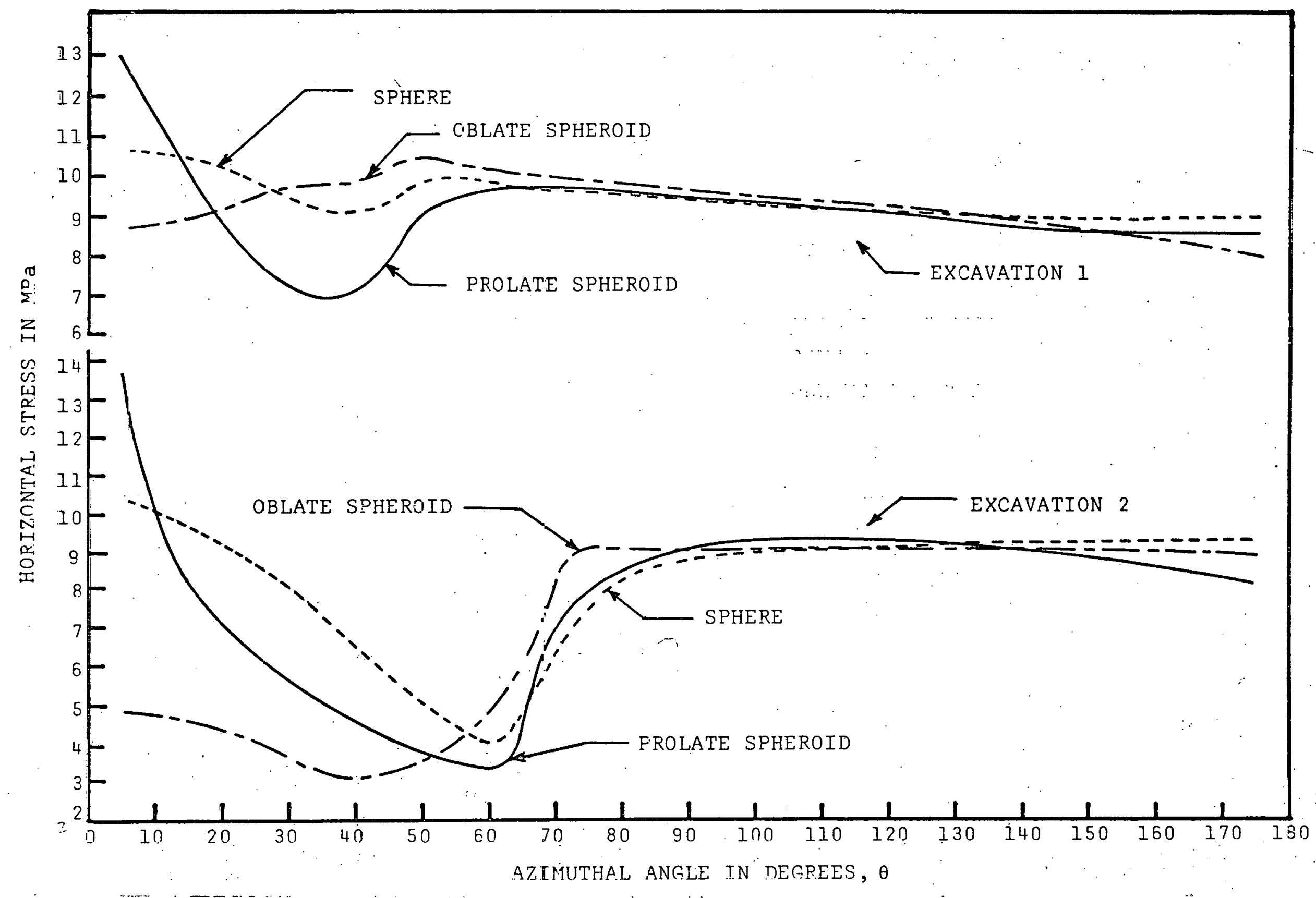

FIGURE 12. HORIZONTAL (RADIAL) STRESS AROUND CAVITIES AFTER FIRST AND SECOND EXCAVATIONS $(K=1)$. 


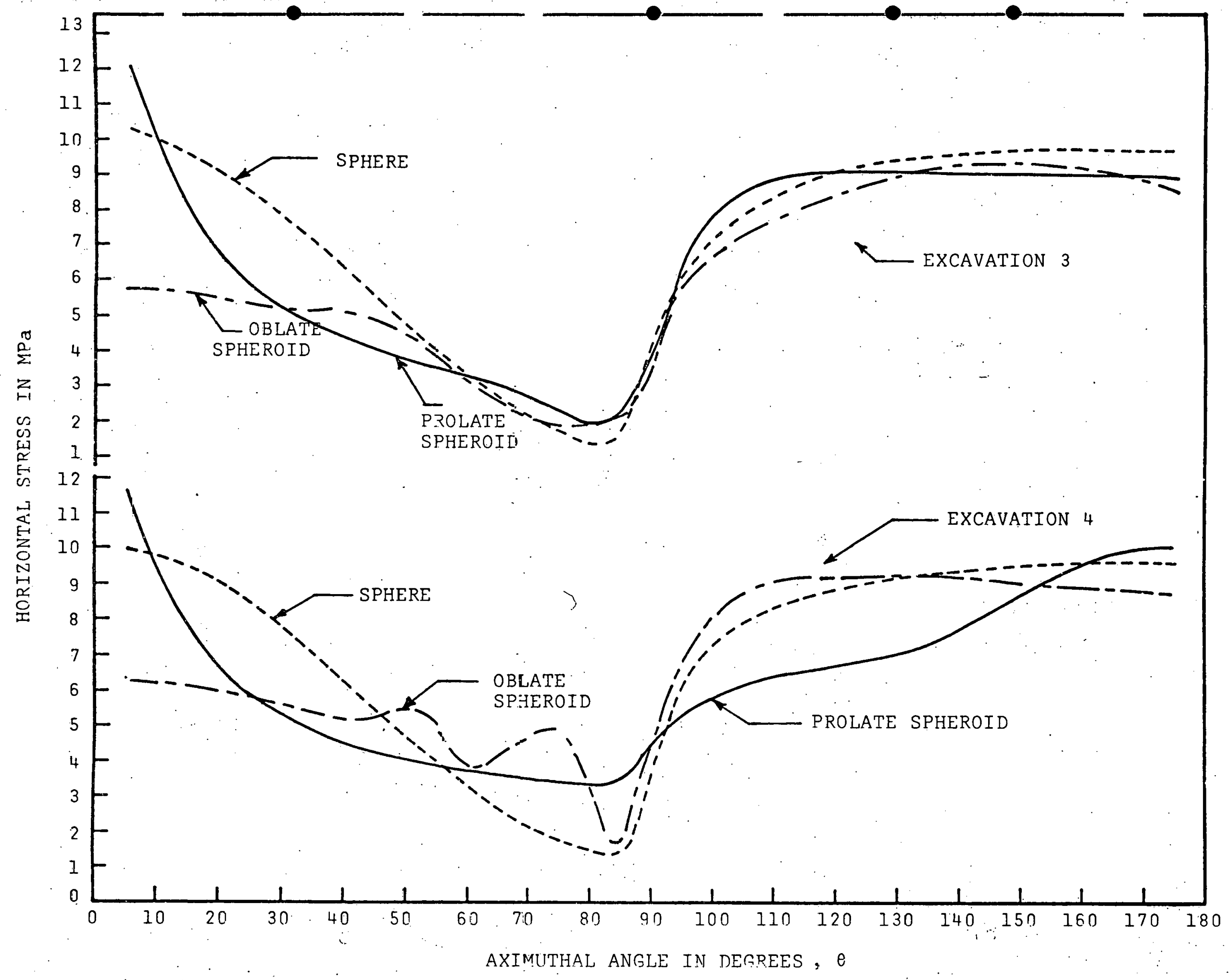




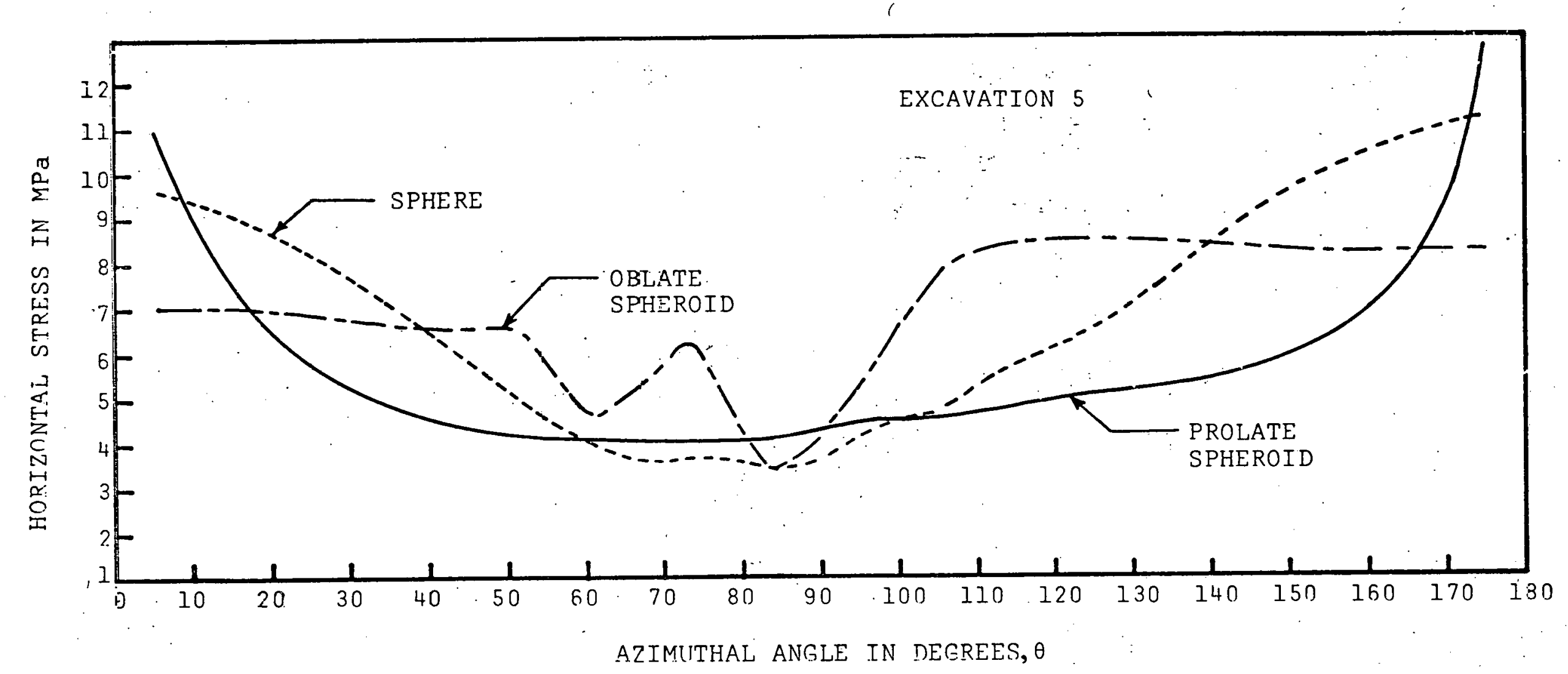

FIGURE 14. HORIZONTAL STRESS (RADIAL) AROUND CAVITIES AFTER FIFTH EXCAVATION $(K=1)$. 


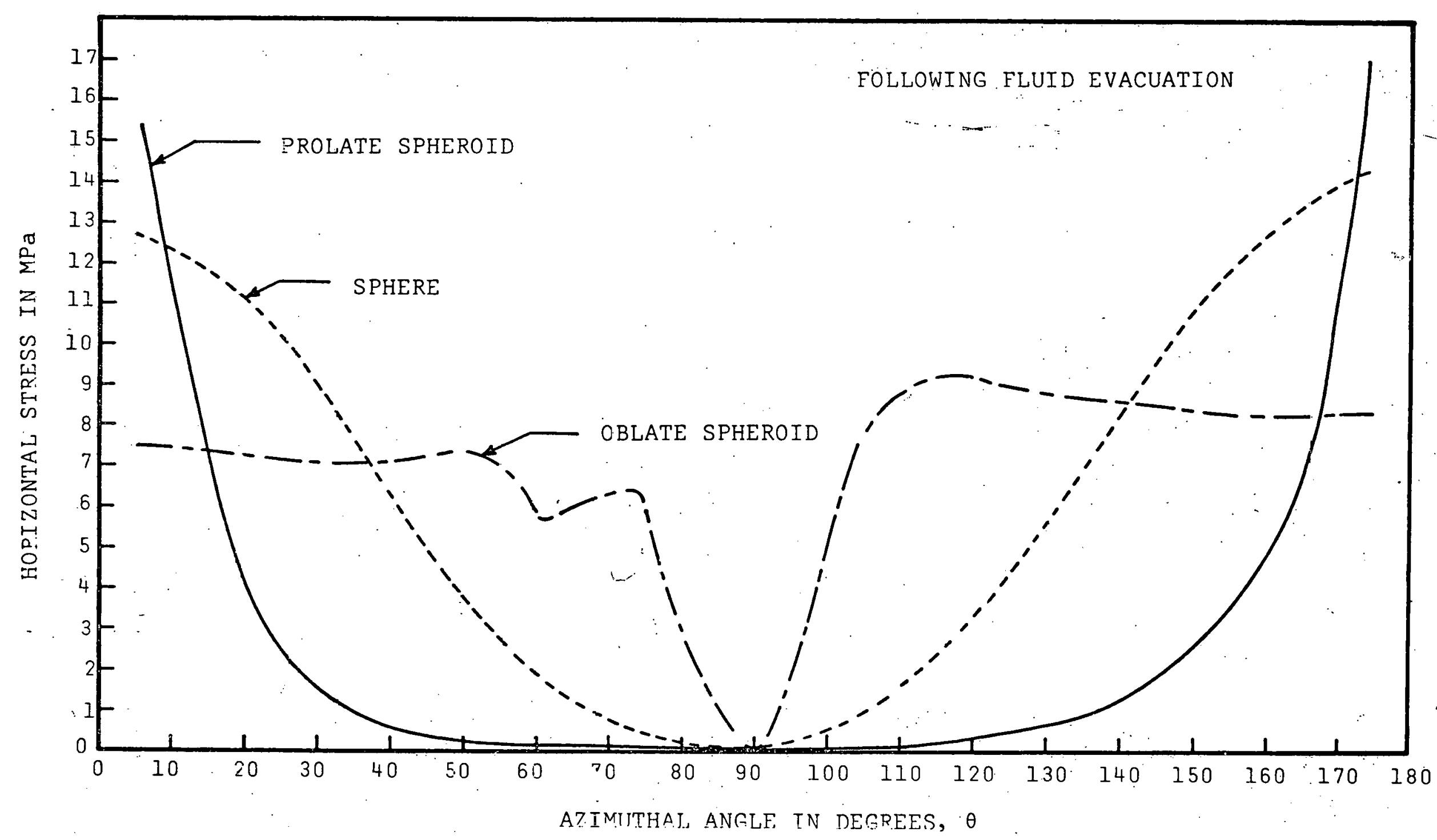

FIGURE 15. FORIZONTAL STRESS (RADIAL) AROUND CAVITIES IMMEDIATELY FOLLOWING FLUID EXCAVATION (K $=1$ ). 


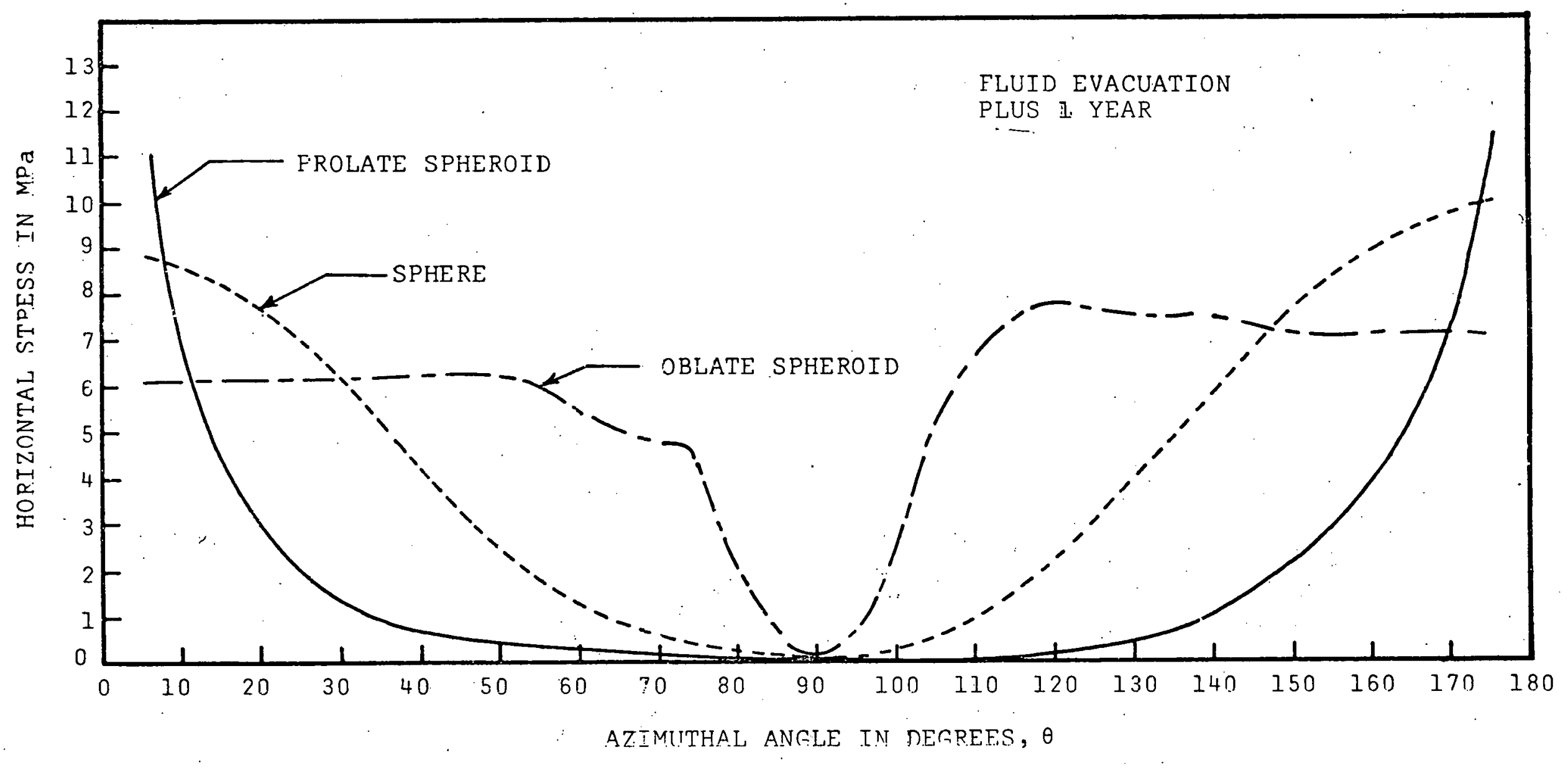

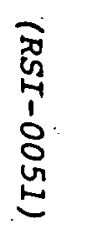

FIGURE 16. HORIZONTAL (RADIAL) STRESS AROUND CAVITIES ONE YEAR AFTER FLUID EXCAVATION (K=1). 


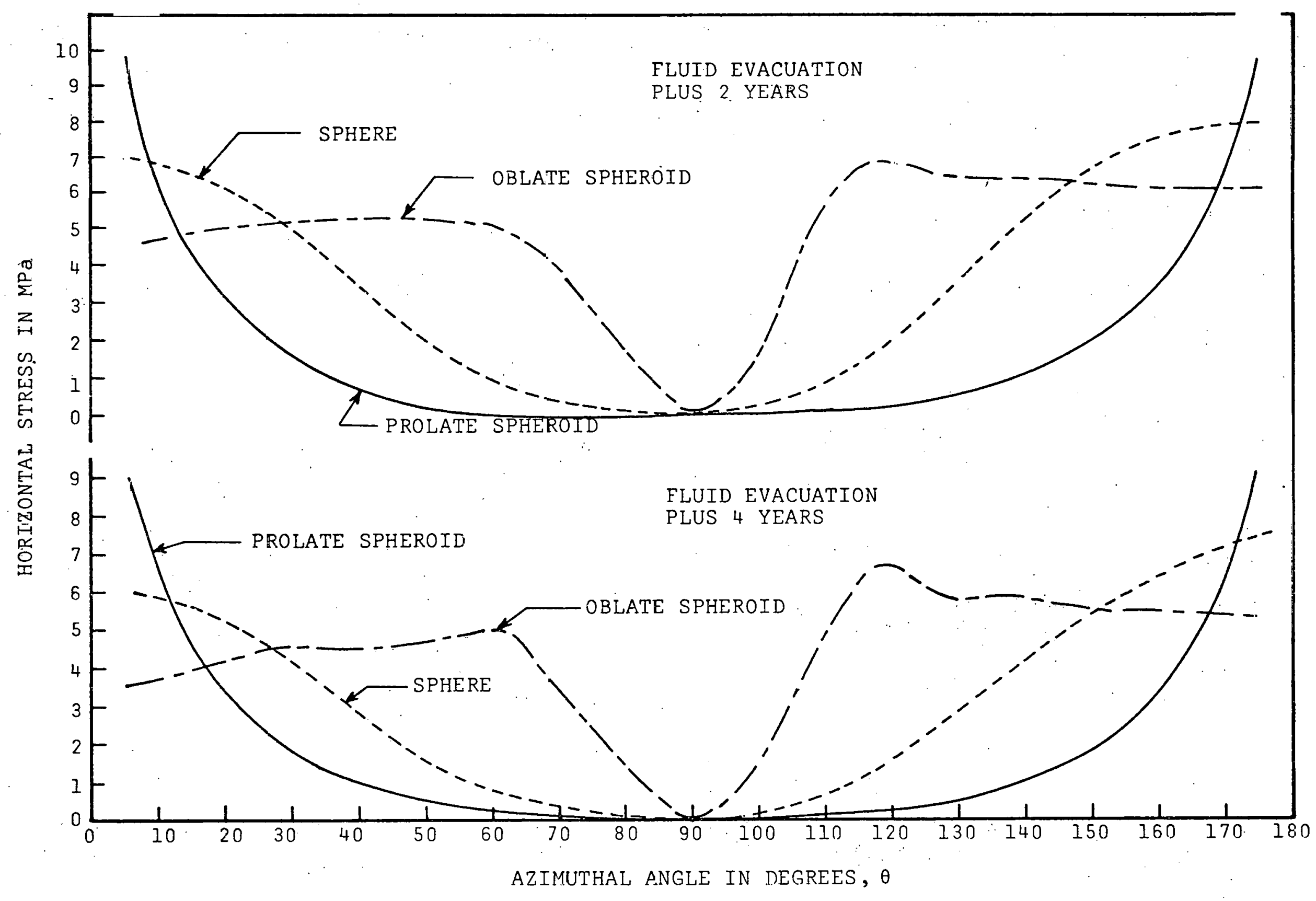

FIGURE 17. HORIZONTAL (RADIAL; STRESS AROUND CAVITIES TWO AND FOUR YEARS AFTER FLUTD EXCAVATION (K = 1). 


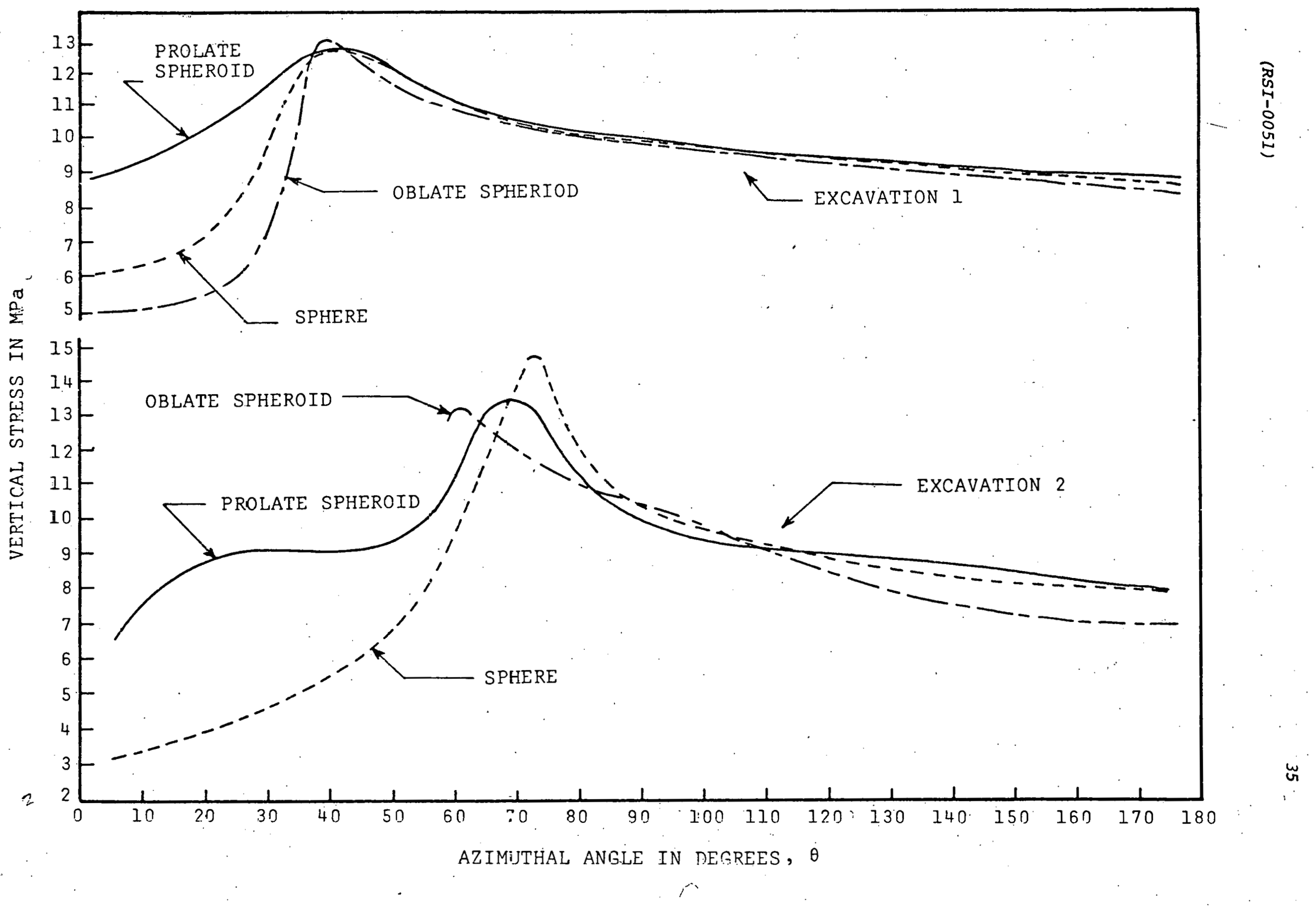

FIGURE 18. VERTICAL STRESS AROUND CAVITIES AFTER FIRST AND SECOND EXCAVATIONS $(K=2)$. 


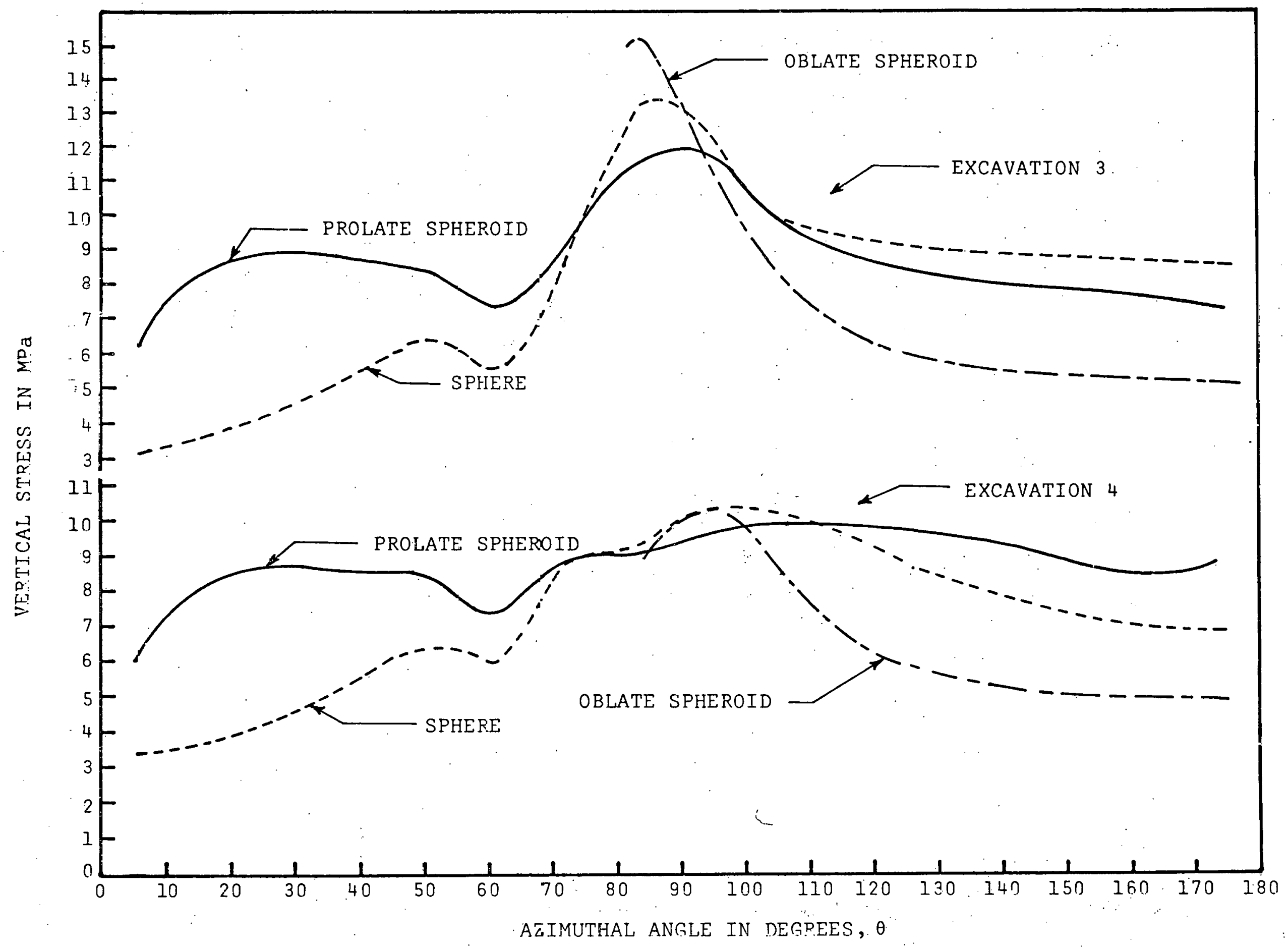

FIGURE 19. VERTICAL STPESS AROUND CAVITIES AFTER THIRD AND FOURTH EXCAVATIONS $(K=1)$. 


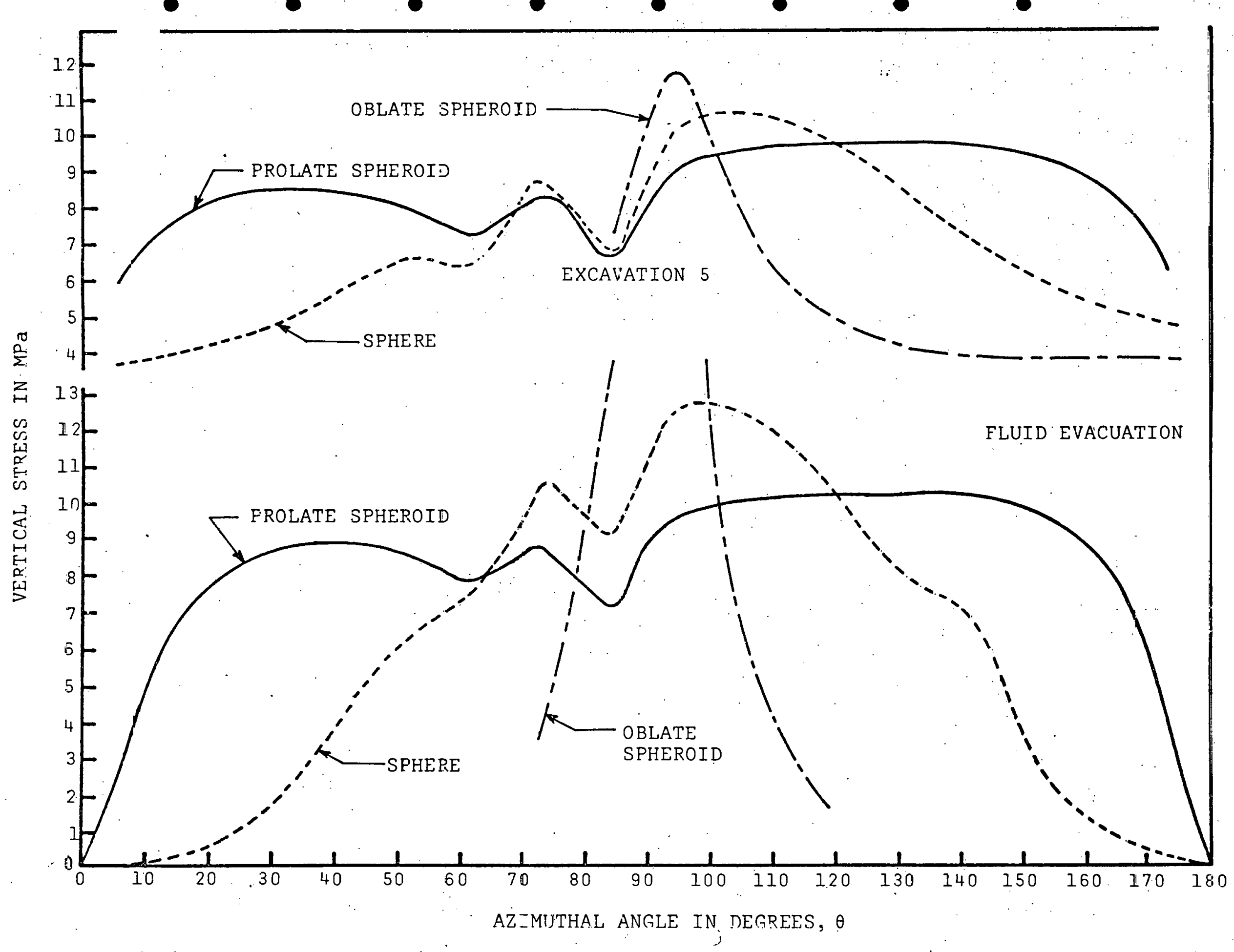

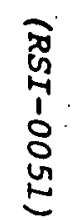

$\underline{w}$

FIGURE 20. VERTICAL STRESS AROUND CAJITIES AFTER FIFTH EXCAVATION AND IMMEDIATELY FOLLOWING FLUID EVACUATION $(K=1)$. 


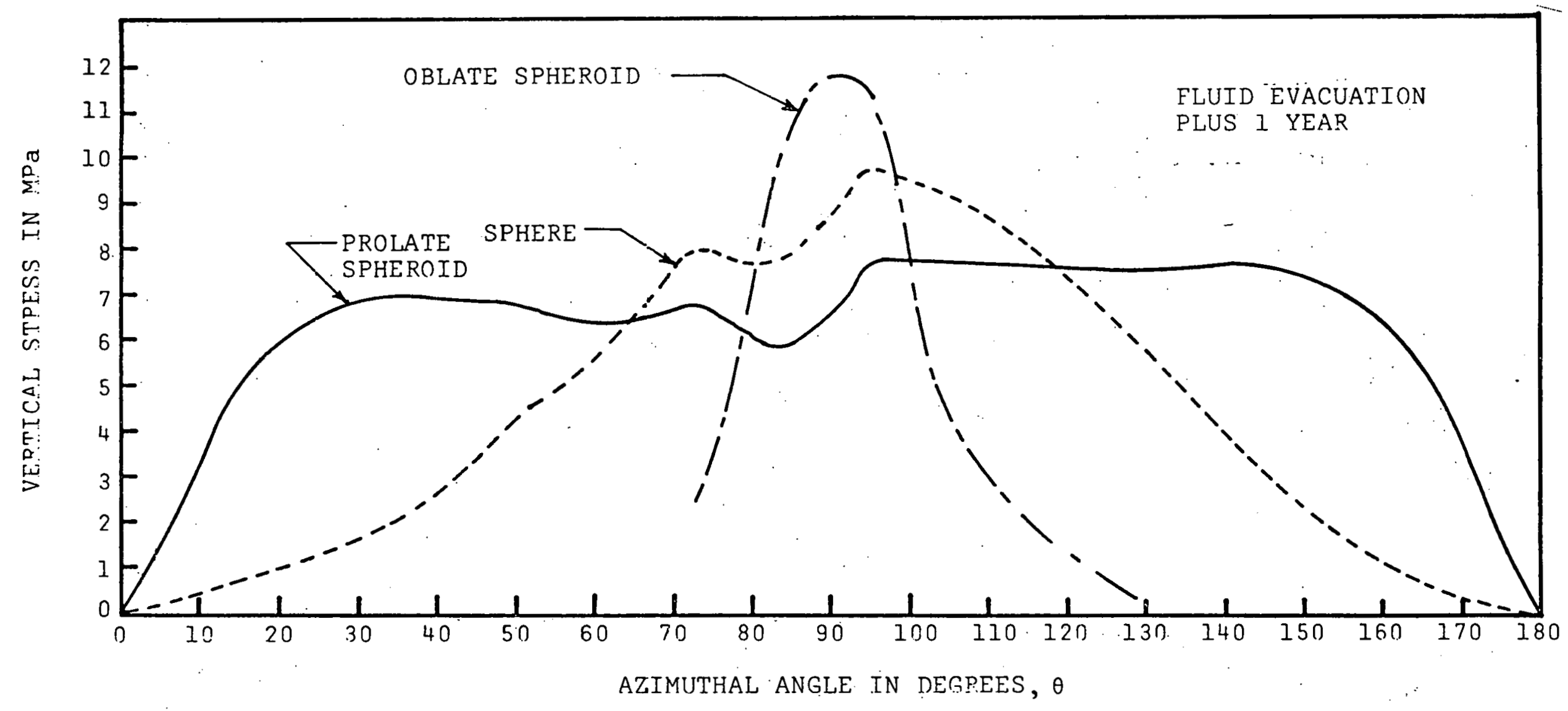

$\underset{\infty}{\omega}$

FIGURE 21. VERTICAL STRESS AROUND CATITIES ONE YEAR AFTER FLUID EVACUATION $(K=1)$. 


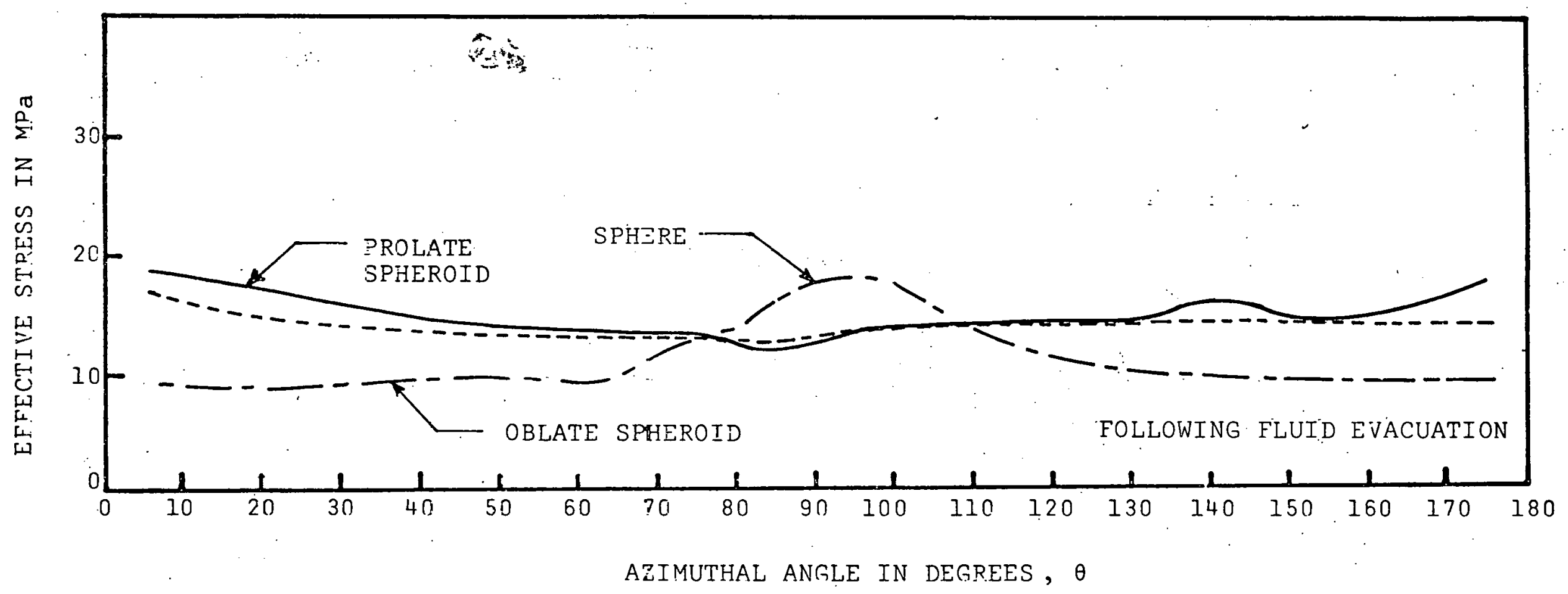

FIGURE 22. EFIECTIVE STRESS AROUND THE CAVITIES $(K=1)$. 


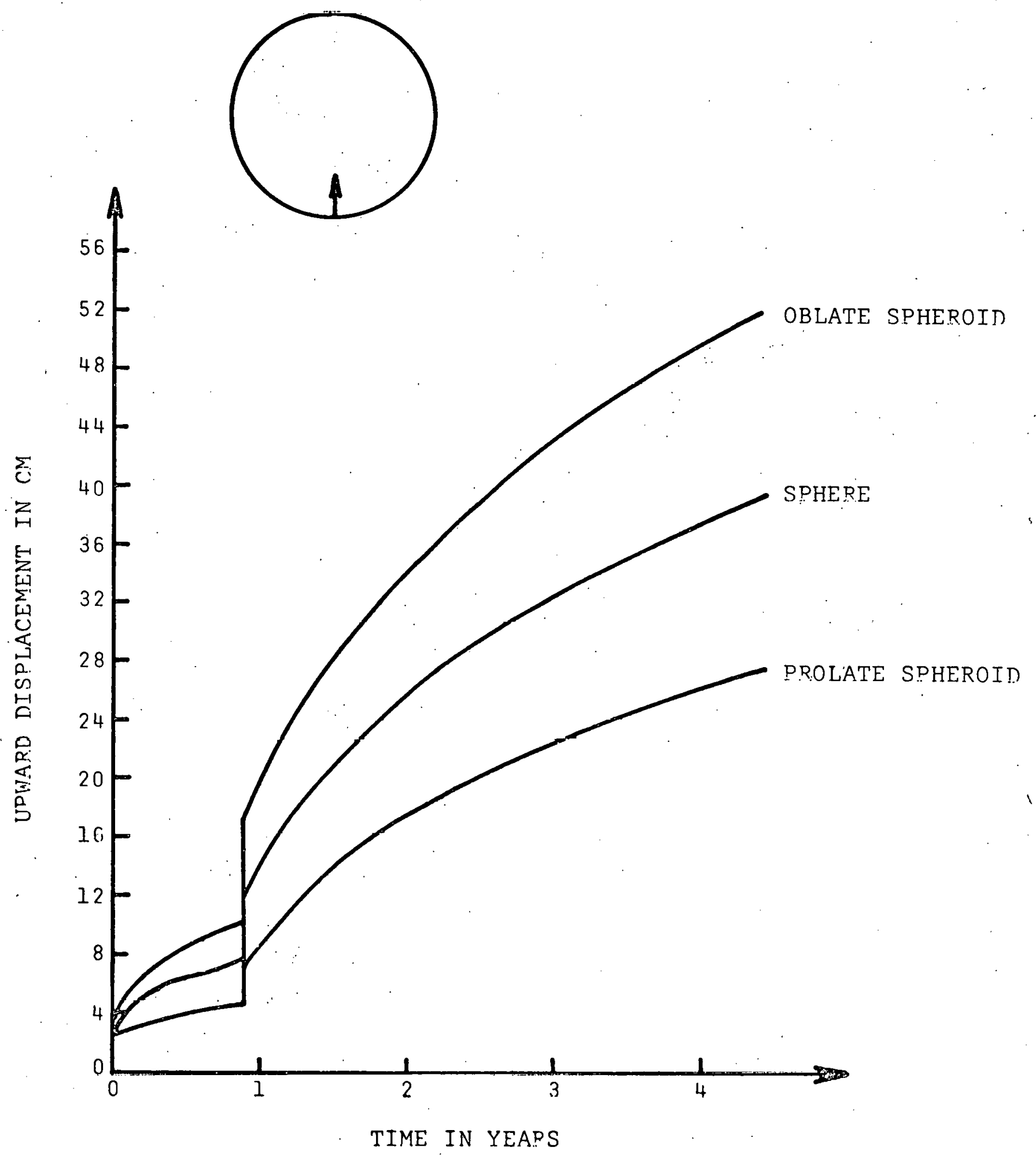

FIGURE 23. UPWARD DISPLACEMENT OF CAVITIES VERSUS TIME $(K=1)$. 


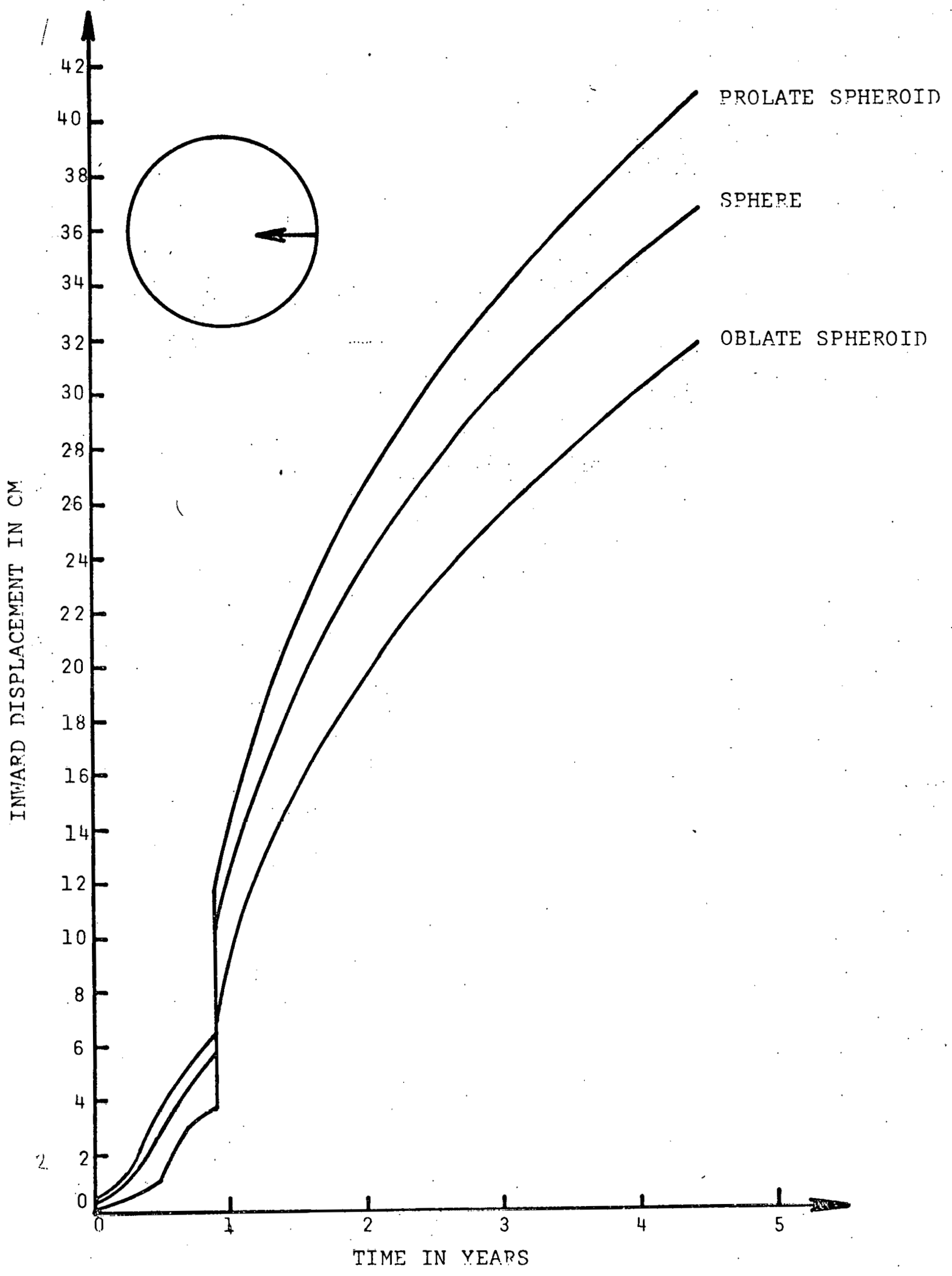

FIGURE 24. INWARD DISPLACEMENT OF CAVITIES VERSUS TIME $(K=1)$. 


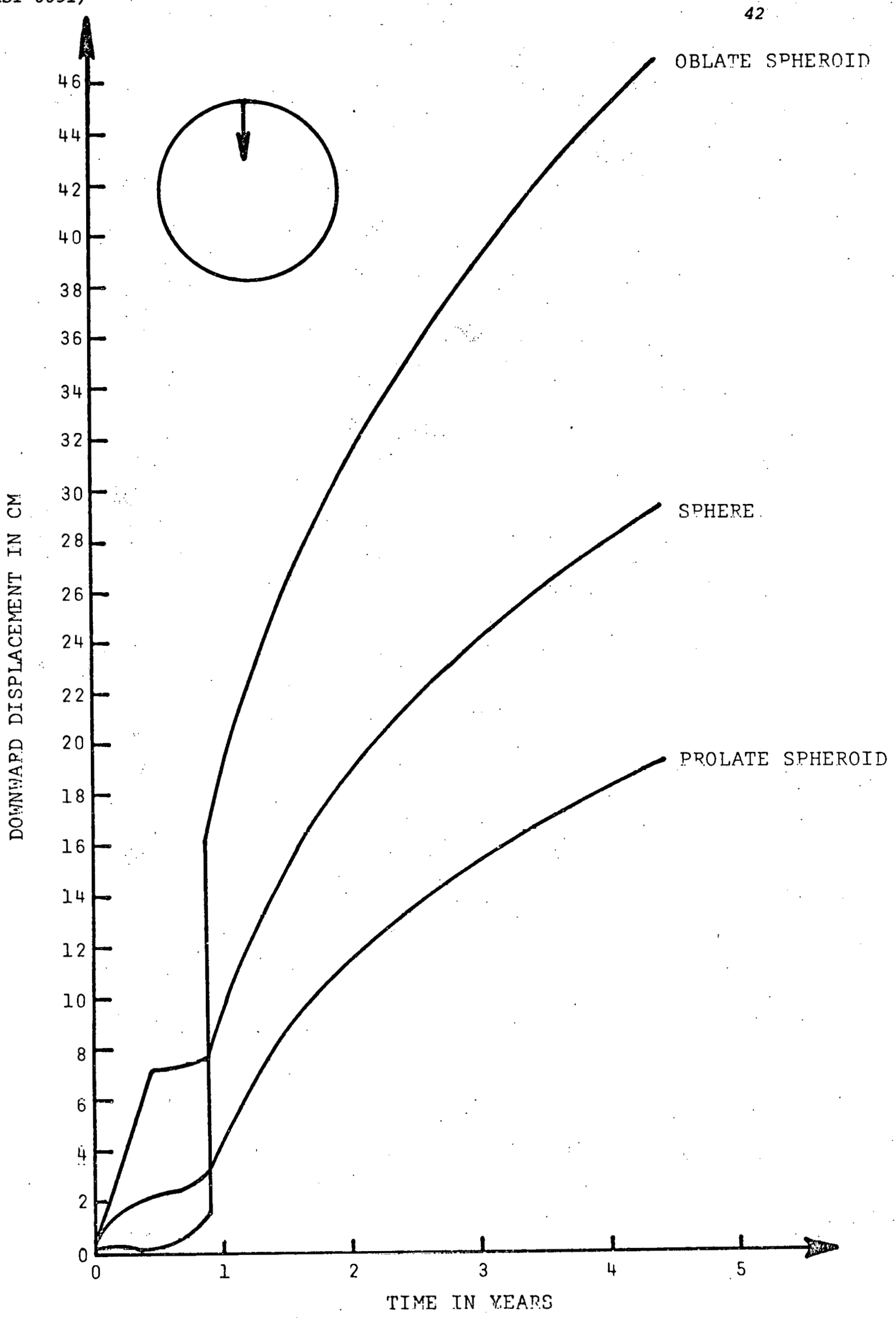

FIGURE 25. DOWNWARD DISPLACEMENT OF CAVITIES VERSUS TIME $(K=1)$. 


\section{LIST OF REFERENCES}

1. Fossum, A. F.: "Structural Analysis of Salt Cavities Formed by Solution Mining: $I$. Method of Analysis and Preliminary Results for Spherical Cavities", Technical Memorand'lm Report RSI-0043, Prepared for Oak Ridge National Laboratory under Subcontract No. 4269 with Union Carbide Corporation, Nuclear Division (January 15, 1976), $31 \mathrm{pp}$. ORNL/SUB-4269/19:

2. Nair, K.; Sandhu, R. S., and Wilson, E. L., "Time-Dependent Analysis of Underground Cavities under Arbitrary Initial Field," Proc. loth Symp. on Rock Mech.., Austin, Texas, 1968.

3. Anderson, C. A., "An Investigation of the Steady Creep of a spherical Cavity in a Half Space," Journal of Applied Mechanics, Vol. 43, Trans. ASME, Vol. 98, Series E, 1976, p. 254.

4. Boresi, A. P. and Deere, D. U., "Creep Closure of a Spherical Cavity in an Infinite Medium," Final report to Holmes \& Narver, Inc., Las Vegas Division, May, 1963.

5. Winkel, B. V., Gerstle, K. H., and Ko, H. Y., "Analysis of TimeDependent Deformations of Openings in Salt Media," Int. J. Rock Mech. Min. Sci. Vol. 9, 1972, p. 249.

6. Gera, F., "Review of Salt Tectonics in Relation to the Disposal of Radioactive Wastes in Salt Formations," Geol. Soc. Amer. Bull., Vol. 83, 1972, p. 3551.

7. Odquist, F.D.G., Mathematical Theory of Creep and Creep Rupture, Oxford University Press, 1966.

8. Finnie, I., "Stress Analysis in the Presence of Creep", Applied Mechanics Reviews, Vol. 13, No. 10, 1960, p. 705.

9. Zienkiewicz, O. C. and Cormeau, I. C., "Visco-Plasticity--Plasticity and Creep in Elastic Solids--A Unified Numerical Solution Approach," Int. Jour. for Numerical Methods in Eng., Vol. 8, 1974, p. 821.

10. Cormeau, I. C., "Numerical Stability in Quasi-Static Elasto-ViscoPlasticity," Int. Jour. for Numerical Methods in Eng., Vol. 9, 1975.

11. Timoshenko, S. and Goodier, J. N., Theory of Elasticity, MCGraw-Hill, New York, 1951. 